\title{
Alteraciones en el reclutamiento y activación de proteínas Rab durante la infección micobacteriana
}

\author{
Diana Castaño ${ }^{1}$, Mauricio Rojas ${ }^{1,2}$ \\ 1 Grupo de Inmunología Celular e Inmunogenética, Instituto de Investigaciones Médicas, Facultad de Medicina, \\ Universidad de Antioquia, Medellín, Colombia \\ 2 Unidad de Citometría de Flujo, Facultad de Medicina, Universidad de Antioquia, Medellín, Colombia
}

En el fagosoma, Mycobacterium spp. altera la activación y reclutamiento de diferentes proteínas "del gen Ras de cerebro de rata", comúnmente conocidas como Rab. En este manuscrito se revisa una serie de reportes que han demostrado que los fagosomas que contienen micobacterias tienen una expresión mayor y sostenida de Rab5, Rab11, Rab14 y Rab22a, y menor o ninguna expresión de Rab7, Rab9 y Rab6. Esto se correlaciona con aumento de la fusión de estos fagosomas con endosomas tempranos y de reciclaje, lo que les permite mantener ciertas características de compartimentos tempranos, permite que las bacterias obtengan acceso a nutrientes y previene la activación de mecanismos contra la micobacteria.

La expresión de mutantes constitutivamente activos de las Rab de endosomas tempranos impide la maduración de fagosomas que contienen esferas de látex o micobacterias inactivadas por calor. Mientras que su silenciamiento, mediante $A R N$ de interferencia o mediante dominantes negativos, induce la maduración de fagosomas micobacterianos. Los mecanismos exactos por los que las micobacterias alteran la dinámica de expresión de estas GTPasas, afectando la maduración fagolisosómica, no se han establecido. El problema podría explicarse por defectos en el reclutamiento de las proteínas que interactúan con Rab, como la cinasa-3 del fosfatidilinositol y el antígeno endosómico temprano 1. La identificación de los mecanismos empleados por Mycobacterium spp. para interrumpir el ciclo de activación de las Rab, será esencial para comprender la fisiopatología de la infección micobacteriana y útil como posibles blancos farmacológicos.

Palabras clave: tuberculosis, Mycobacterium tuberculosis, proteínas de unión a GTP rab, proteínas SNARE, fagosomas, endosomas.

\begin{abstract}
Alterations in recruitment and activation of Rab proteins during mycobacterial infection
At the phagosome level, Mycobacterium spp. alters activation and recruitment of several "Ras gene from rat brain" proteins, commonly known as Rab. Mycobacterial phagosomes have a greater and sustained expression of Rab5, Rab11, Rab14 and Rab22a, and lowered or no expression of Rab7, Rab9 and Rab6. This correlates with increased fusion of the phagosomes with early and recycling endosomes acquiring some features of early phogosomes, allowing the bacteria to gain access to nutrients and preventing the activation of anti-mycobacterial mechanisms.

The expression of constitutively active mutants of Rab from the early stage endosomes prevents the maturation of phagosomes containing latex beads or heat-inactivated mycobacteria. Silencing of these mutants by interference RNA or dominant negative forms induces the maturation of mycobacterial phagosomes. The mechanisms have not been established by which mycobacteria alter the expression of these GTPases and thereby shift the phagolysosomal maturation. The problem can be explained by alterations in the recruitment of proteins that interact with Rab, such as phosphoinositide 3-kinases and early endosomal antigen 1. Identifying the mechanisms used by Mycobacterium spp. to disrupt the cycle of Rab activation will be essential to understand the pathophysiology of mycobacterial infections and usefully to potential drug targets.
\end{abstract}

Key words: tuberculosis, Mycobacterium tuberculosis, rab GTP-binding proteins, SNARE proteins, phagosomes, endosomes.

\author{
Correspondencia: \\ Mauricio Rojas, Sede de Investigación Universitaria, Universidad \\ de Antioquia, Carrera 53 № 61-30, laboratorio 420, Medellín, \\ Colombia. \\ Teléfono: (574) 219 6461; fax: (574) 2196463 \\ mrojas|@une.net.co
}

Recibido: 31/03/09; aceptado: 28/01/10
El funcionamiento adecuado de las células eucarióticas requiere del intercambio de macromoléculas con su entorno y entre sus organelas. Esto se logra por medio de un sistema de transporte complejo de vesículas y de las moléculas asociadas. Existen múltiples hallazgos 
que indican que desde los eventos más tempranos de la infección con Mycobacterium tuberculosis hay alteraciones en el tránsito vesicular que pueden ser definitivas en el curso de la infección $(1,2)$. En la primera parte de esta revisión, se resumen algunos aspectos generales del tránsito vesicular para el mejor entendimiento de la segunda parte, en la que se revisan los hallazgos experimentales sobre la modulación de las proteínas Rab durante la infección micobacteriana.

En el interior de las células existe una comunicación constante mediante la gemación de vesículas a partir de membranas donantes que, posteriormente, se fusionan con compartimentos aceptores o blanco. Se han definido dos clases de transporte de membrana principales: uno, del interior hacia el exterior de la célula, la vía secretoria o biosintética $y$, otro, en el sentido contrario, denominado endocitosis (3).

En la vía secretoria, los polipéptidos que se generan a partir de la traducción del ARN mensajero, se pliegan y se ensamblan por medio de chaperonas residentes en el retículo endoplásmico; de lo contrario, son retenidas $y$, eventualmente, destruidas en el proteasoma o su acumulación induce mecanismos de muerte celular (4). Desde el retículo endoplásmico las proteínas se transportan al aparato de Golgi (entrando por la red
cis-Golgi), donde tiene lugar la mayor parte de las modificaciones posteriores a la traducción, como la glucosilación. Las proteínas modificadas salen por el trans-Golgi empaquetadas en vesículas destinadas a unirse con endosomas, lisosomas, organelas, membrana plasmática y con vesículas secretorias o exocíticas, las cuales pueden ser secretorias constitutivas y reguladas (5).

La endocitosis es el proceso por el cual una célula toma macromoléculas, partículas e, inclusive, otras células del espacio extracelular, las encierra en una porción de membrana que se invagina $y$, posteriormente, las separa de la membrana plasmática. Seconocen, principalmente, tres formas de endocitosis (figura 1): la endocitosis mediada por receptores, la fagocitosis y la pinocitosis.

En la endocitosis mediada por receptores, éstos median el reconocimiento de la molécula y la polimerización de trisqueliones de clatrina que recubren la vesícula endocítica que se ha generado $(6,7)$.

La fagocitosis también requiere de un receptor que participe en el reconocimiento de la partícula por fagocitar y, además, que medie la formación de una vesícula por rearreglos de la actina del citoesqueleto y no por polimerización de clatrina, ya que las partículas tomadas por esta vía son de gran tamaño.

\section{A. Pinocitosis}

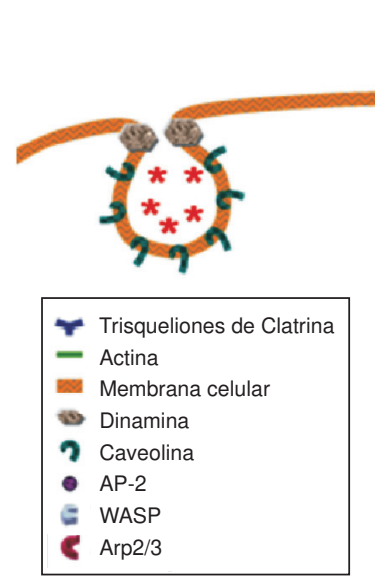

B. Endocitosis mediada por receptor

\section{Fagocitosis}

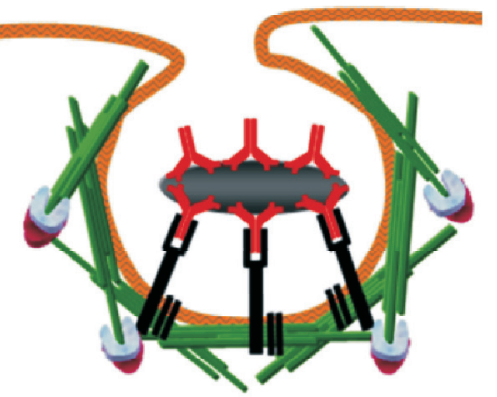

Figura 1. Formas de endocitosis. Se representan las principales formas de endocitosis descritas de manera simplificada y en escala de tamaño. A. Pinocitosis. Se observa el ingreso de componentes solubles del espacio extracelular por invaginación de la membrana, mediante la participación de la caveolina y la dinamina. B. Endocitosis mediada por receptor. Se presenta la endocitosis de hierro acoplado a transferrina mediada por el reconocimiento del receptor de transferrina, el cual induce una señalización que promueve el reclutamiento de la proteína adaptadora 2 (AP-2), la dinamina y la polimerización de trisqueliones de clatrina. C. Fagocitosis. Se observa la fagocitosis de un bacilo medida por receptores para la porción Fc de inmunoglobulinas G que lleva a la activación de varias proteínas, entre ellas, cinasas de tirosinas, el complejo Arp 2/3 y la proteína del síndrome de Wiskott-Aldrich (las dos últimas se representan en la figura), las cuales estimulan la polimerización de actina. 
En la pinocitosis se observa una invaginación de la membrana que permite el ingreso de fluidos y solutos sin participación de receptores ni polimerización del citoesqueleto y la clatrina; sin embargo, al parecer, depende de la composición de lípidos y de la presencia de una proteína de membrana conocida como caveolina, la cual se asocia con los dominios ricos en colesterol y esfingolípidos y media la formación de pequeñas invaginaciones en la membrana denominadas caveolas $(5,6)$.

Actualmente, se hace referencia a otra forma de endocitosis independiente de la clatrina, la cual se desencadena en respuesta a diferentes moléculas de superficie (receptores o proteínas virales) y lípidos de la membrana plasmática, mediante el reclutamiento de caveolina (6).

Los lisosomas convergen tanto por la vía secretoria como por la endocítica. Los lisosomas son estructuras ácidas $(\mathrm{pH} \leq 5,5)$ y con un alto contenido de proteasas y lipasas activas. Las macromoléculas endocitadas son "entregadas" secuencialmente a endosomas tempranos, endosomas tardíos y lisosomas, mediante la fusión con componentes provenientes del aparato de Golgi; en estos últimos compartimientos se ensambla la bomba de hidrogeniones ATPasa, que media la acidificación y facilita la activación de enzimas dentro de los lisosomas. Algunas de las moléculas que sufren endocitosis son devueltas a la membrana plasmática por medio de endosomas de reciclaje $(3,5)$.

Las vesículas intracelulares se forman de regiones de las membranas (membrana donante) revestidas con diferentes proteínas (que forman una cubierta), las cuales concentran las moléculas que conforman la vesícula y permiten su separación del compartimiento donador. La cubierta puede estar formada por proteínas que participan diferencialmente en la formación y transporte de las vesículas: actina, clatrina, COP-I (coated protein I) y COP-II. Por ejemplo, hallazgos recientes indican que la actina participa en la generación y en el transporte de los endosomas (D. Castaño, datos sin publicarse) y fagosomas; la clatrina participa del transporte hacia y desde el aparato de Golgi y la membrana plasmática; mientras que las COP participan del transporte hacia y desde el retículo endoplásmico y el aparato de Golgi (3).

La especificidad de la fusión entre endosomas y fagosomas se encuentra controlada, principalmente, por dos clases de proteínas: las SNARE
( $N$-ethylmaleimide sensitive factor accessoryprotein, SNAP, receptors) y las Rab (Ras gene from rat brain). Las SNARE son las responsables del anclaje y la fusión de las vesículas con su membrana blanco, mientras que las Rab regulan las diferentes etapas de maduración y transporte vesicular $(5,8)$. Algunas generalidades de la maduración fagosómica y el papel de estas proteínas en el tránsito y la fusión vesicular se describen con mayor claridad a continuación.

\section{Maduración de fagosomas}

Durante la fagocitosis, el receptor involucrado puede activar diferentes vías de señalización, rearreglos de la actina del citoesqueleto y la formación de un compartimiento membranoso denominado fagosoma $(9,10)$. La membrana de los fagosomas recién formados es similar a la plasmática y su contenido, a los fluidos del espacio extracelular (11). Para degradar las partículas ingeridas, estos fagosomas deben madurar hacia compartimientos ácidos e hidrolíticos.

Aunque no es completamente claro cómo ocurre dicha maduración, se han descrito muchas similitudes con la vía endocítica (12). Este proceso se da por una serie de fusiones y fisiones complejas de los fagosomas con elementos vesiculares de la red endosómica, como: endosomas tempranos, endosomas de reciclaje, endosomas tardíos y, finalmente, con lisosomas (13).

Aunque este proceso es continuo, se pueden diferenciar tres etapas secuenciales principales caracterizadas por la expresión local de marcadores específicos (figura 2): los fagosomas tempranos, se forman tras la fusión de un fagosoma con un endosoma temprano y se caracterizan por un bajo contenido de proteasas y un $\mathrm{pH} \sim 6,0$; expresan moléculas como la GTPasa Rab5, la proteína efectora de Rab5, el antígeno endosómico temprano 1 (EEA-1), el receptor de transferrina que une y transporta el hierro a estos compartimentos y la molécula asociada al citoesqueleto coronina I (TACO), entre otras.

Desde estos fagosomas tempranos se da una recirculación de proteínas a la membrana plasmática que se hace por medio de endosomas de reciclaje, que son molecular y bioquímicamente diferentes a los endosomas tempranos, son menos ácidos $(\mathrm{pH} \sim 6,5)$ y se caracterizan por la presencia de Rab11 (11).

Los fagosomas tardíos resultan de la fusión de un fagosoma temprano con un endosoma tardío, 


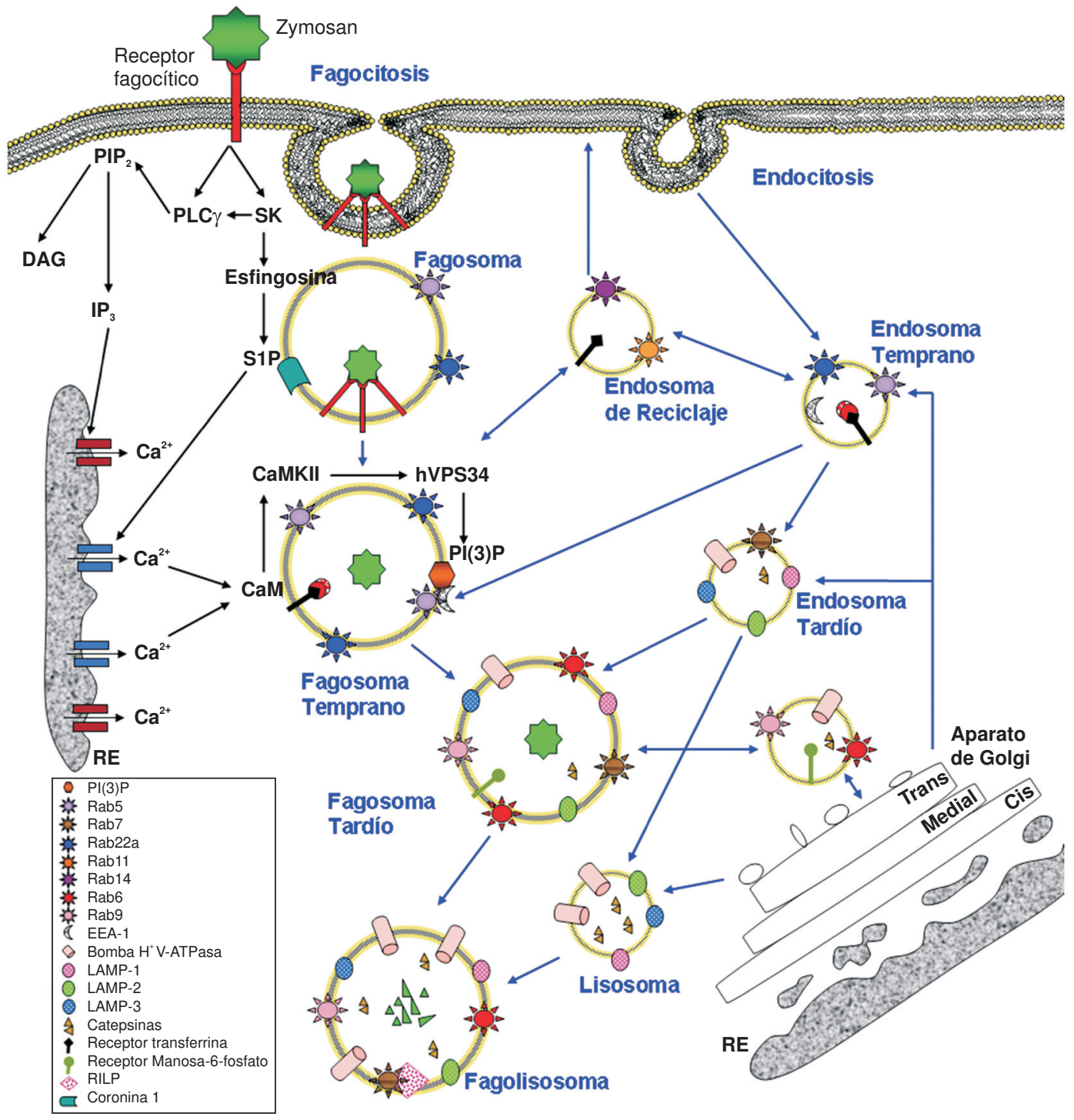

Figura 2. Esquema en el que se propone cómo podrían ser los eventos que conducen a la maduración de fagosomas. En el gráfico se presenta de forma resumida un consenso general de cómo ocurre la maduración de fagosomas y endosomas en fagocitos mononucleares, así como las principales moléculas asociadas con cada uno de los estadios y la vía de señalización acoplada a dicha maduración.

alcanzan un $\mathrm{pH}$ de 5,5 y son ricos en hidrolasas; mientras los fagolisosomas resultan de la fusión final de estas estructuras membranosas con lisosomas y alcanzan un $\mathrm{pH}$ menor de 5,5. Los fagosomas tardíos y los fagolisosomas, tienen gran cantidad de enzimas hidrolíticas, péptidos antimicrobianos (defensinas y derivados de la ubicuitina) y la capacidad de generar compuestos tóxicos de oxidación; expresan marcadores como las proteínas de membrana asociadas a lisosomas uno (LAMP-1 o CD107a), dos (LAMP-2 o CD107b) $y$ tres (LAMP-3 o CD63), diferentes isoformas activas de las catepsinas y una bomba de protones ATPasa, entre otros (11,14-16).

Desde el punto de vista funcional, los procesos asociados con la ingestión de partículas conducen a un incremento en el $\mathrm{Ca}^{2+}$ del citosol, indispensable para la maduración de los fagosomas y los mecanismos asociados con la actividad bactericida (17). El $\mathrm{Ca}^{2+}$ es inducido tras la activación de esfingosina cinasa y fosfolipasa C gamma. La esfingosina cinasa fosforila la esfingosina produciendo la esfingosina 1 fosfato (S1P) (18). Ésta se une a receptores de membrana 
citoplasmática y del retículo endoplásmico y libera $\mathrm{Ca}^{2+}$. La fosfolipasa $\mathrm{C}$ gamma, por medio de la generación de inositol trifosfato $\left(\mathrm{IP}_{3}\right)$, también induce movilización de $\mathrm{Ca}^{2+}(19)$. El calcio activa la calmodulina (CaM), la cual regula la fusión endosómica al translocarse a la membrana de los fagosomas recién formados (20), fosforilando y activando a la cinasa II dependiente de calmodulina (CaMKII) (16); que, a su vez, fosforila a la cinasa III del fosfatidilinositol (PI3K o hVPS34). Esta última cataliza la formación del fosfatidilinositol trifosfato $[\mathrm{PI}(3) \mathrm{P}]$ fosforilando el fosfatidilinositol en la membrana del fagosoma $(15,21)$.

La Rab5 y la Rab7 controlan las interacciones secuenciales de endosomas tempranos y tardíos con los fagosomas. La Rab5 se expresa, principalmente, en endosomas tempranos y la Rab7, en compartimientos endocíticos tardíos (22). El PI(3) $P$, junto con la Rab5, son los puntos de anclaje para la unión del EEA-1, el cual es un regulador de la fusión de los fagosomas tempranos con los endosomas tardíos y lisosomas (23).

El paso de endosoma temprano a tardío, además de estar mediado por la expresión de EEA-1, requiere de un proceso denominado "conversión de Rab", en el cual se intercambia Rab5 por Rab7 (17). Aunque las señales que desencadenan este cambio no se conocen con claridad, se sabe que requiere de la acumulación de EEA-1 en la membrana del fagosoma para la adquisición de Rab7.

Finalmente, todo esto permite que los endosomas tardíos y los lisosomas se acoplen a fagosomas, favoreciendo el ensamble de los componentes necesarios para la degradación de los elementos ingeridos, como la bomba de protones $\mathrm{VoH}^{+}$ ATPasa, necesaria para la acidificación de estos compartimientos. Este proceso favorece la activación de las enzimas lisosómicas, así como del sistema NADPH oxidasa y la óxido nítrico sintasa inducible (iNOS). Los productos de estos sistemas son importantes agentes antimicrobianos que median la destrucción de los elementos fagocitados (figura 3) (10). Además de la interacción con la red endosómica, los fagosomas tienen un contacto directo con componentes que provienen del retículo endoplásmico $(24,25)$.

Actualmente, se postula que los componentes tardíos o lisosómicos pueden llegar a los fagosomas, al menos, por dos vías diferentes: una dependiente de PI3K, que participa principalmente en la adquisición de hidrolasas, y la otra, independiente, que participa en la adquisición de proteínas integrales de la membrana, como la bomba de protones ATPasa (26).

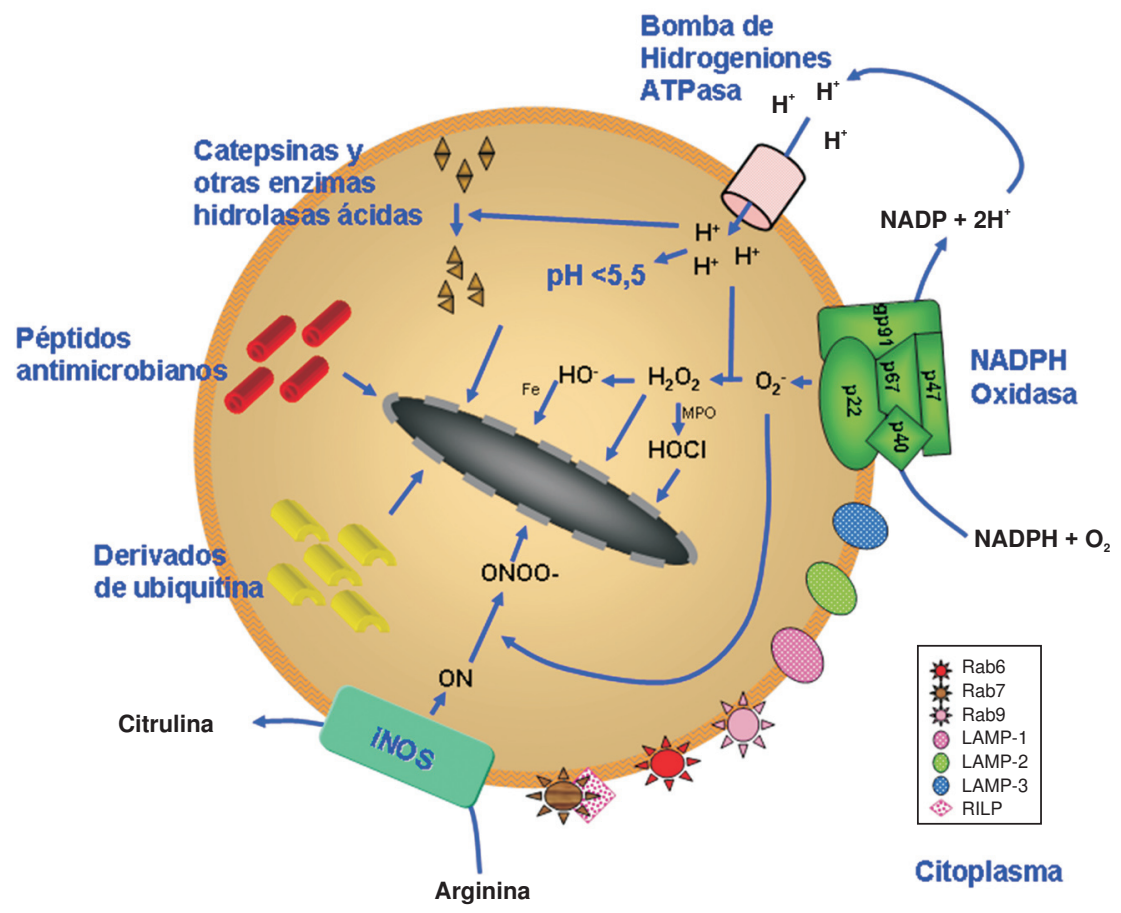

Figura 3. Mecanismos microbicidas. Se ilustra un fagolisosoma con los principales mecanismos microbicidas dependientes e independientes de oxígeno que se activan en fagocitos mononucleares para la destrucción de los agentes fagocitados. 


\section{Proteínas SNARE}

Como se mencionó anteriormente, las proteínas SNARE y Rab son las responsables de regular y mediar la interacción de endosomas y fagosomas. Los miembros de la familia SNARE son los principalescatalizadores delafusión demembranas. Sus mecanismos se consideran evolutivamente conservados desde levaduras hasta humanos. Múltiples SNARE regulan los eventos de fusión requeridos para la maduración de los fagosomas a compartimentos ácidos e hidrolíticos.

Se conocen, hasta el momento, 38 proteínas de esta familia en mamíferos, cada una asociada con una organela o vesícula particular (27). La mayoría de las SNARE son proteínas integrales de membrana que tienen forma de hélice a. Poseen un motivo SNARE, que media la interacción SNARE-SNARE, el cual está conformado por siete repeticiones de 60 a 70 aminoácidos. Estas proteínas funcionan como grupos complementarios: la SNARE de una membrana donante une a una SNARE sobre una membrana blanco, dándole especificidad a la fusión (28).

En cada vesícula existe una proteína llamada v-SNARE (debido a su origen vesicular), mientras que en, las membranas blanco, se designan t-SNARE (target). Ciertas moléculas v-SNARE se unen con determinados t-SNARE mediante la interacción de las hélices de cada proteína que se envuelven entre sí formando unos complejos conocidos como trans-SNARE, los cuales inmovilizan, acercan y median la unión de las membranas involucradas (29).

Esta clasificación basada en la localización y función de las SNARE no siempre se conserva, por lo que se emplea otra terminología basada en la estructura de estas proteínas. Dependiendo de la presencia de un residuo de arginina ( $R$ ) o glutamina $(Q)$ en su motivo SNARE, se han dividido estas proteínas en R-SNARE (usualmente, en vesículas) y Q-SNARE (usualmente, en las membranas blanco). Las R-SNARE se encuentran conformadas por una sola cadena polipeptídica, mientras las Q-SNARE (subdivididas en $\mathrm{Qa}$; $\mathrm{Qb}$; $\mathrm{Qc}$ y $\mathrm{Qb}, \mathrm{c}$ ) funcionan como un complejo multiproteico conformado generalmente por tres polipéptidos (27).

Los complejos trans-SNARE están integrados por la interacción entre cuatro hélices, una de R-SNARE y tres de Q-SNARE, y en presencia de $\mathrm{Ca}^{2+}$ son suficientes para la fusión de los fosfolípidos de membranas opuestas (figura 4).
La superficie de las vesículas tiene una carga neta negativa debido al grupo fosfato presente en la cabeza de los fosfolípidos, que previene la unión de las membranas opuestas. Sin embargo, cuando se forma un trans-SNARE se propicia un acercamiento de las membranas, lo que permite que el $\mathrm{Ca}^{2+}$ se una con dos grupos fosfatos, cada uno perteneciente a un fosfolípido de las membranas opuestas, estableciendo un enlace iónico entre ellas y permitiendo la interacción de los lípidos de membrana que conduce a la fusión de las membranas adyacentes (30). Una vez se completa la fusión, las SNARE unidas a la membrana blanco reciben el nombre de cis-SNARE (figura 4).

Posteriormente, estas proteínas se separan en sus componentes R-SNARE y Q-SNARE mediante el reconocimiento del complejo cis-SNARE por a-SNAP y por la acción de la ATPasa NSF ( $N$-ethylmaleimide sensitive factor) que interactúa con a-SNAP (figura 4) (28).

\section{Rab GTPasas}

Las Rab son proteínas que regulan la fusión y el transporte intracelular de membranas y vesículas en las células eucarióticas. Participan tanto de la vía endocítica como de la exocítica. Se cree que estas proteínas facilitan y regulan la cinética del anclaje y apareamiento de v-SNARE y t-SNARE. También, activan otras proteínas efectoras que acercan las vesículas a su membrana blanco; intervienen en la fusión, acelerando y dirigiendo este proceso. Se sabe que los complejos multiproteicos que incluyen a las Rab, las SNARE y a otras proteínas de anclaje, permiten la interacción inicial entre dos vesículas con la posterior fusión de las membranas de cada una (8).

Las proteínas Rab fueron descritas en la década de los 80; hacen parte de la superfamilia de las pequeñas GTPasas monoméricas (20 a $29 \mathrm{kDa}$ ) Ras. Se conocen $11 \mathrm{Rab}$ en levaduras y, al menos, 63 variantes en mamíferos; éstas comparten entre $54 \%$ y $71 \%$ de homología y pueden estar restringidas a diferentes tejidos, células y a localizaciones subcelulares especializadas, lo que permite asociarlas con ciertas vesículas o transportes específicos $(31,32)$.

Las Rab regulan diferentes pasos en las vías de transporte vesicular intracelular, como la formación de la vesículas (por ejemplo, Rab9 y Rab11), la movilidad de vesículas (Rab5 y Rab6), el remodelado de la membrana vesicular (Rab5 y sus proteínas efectoras), el acoplamiento de las 
1
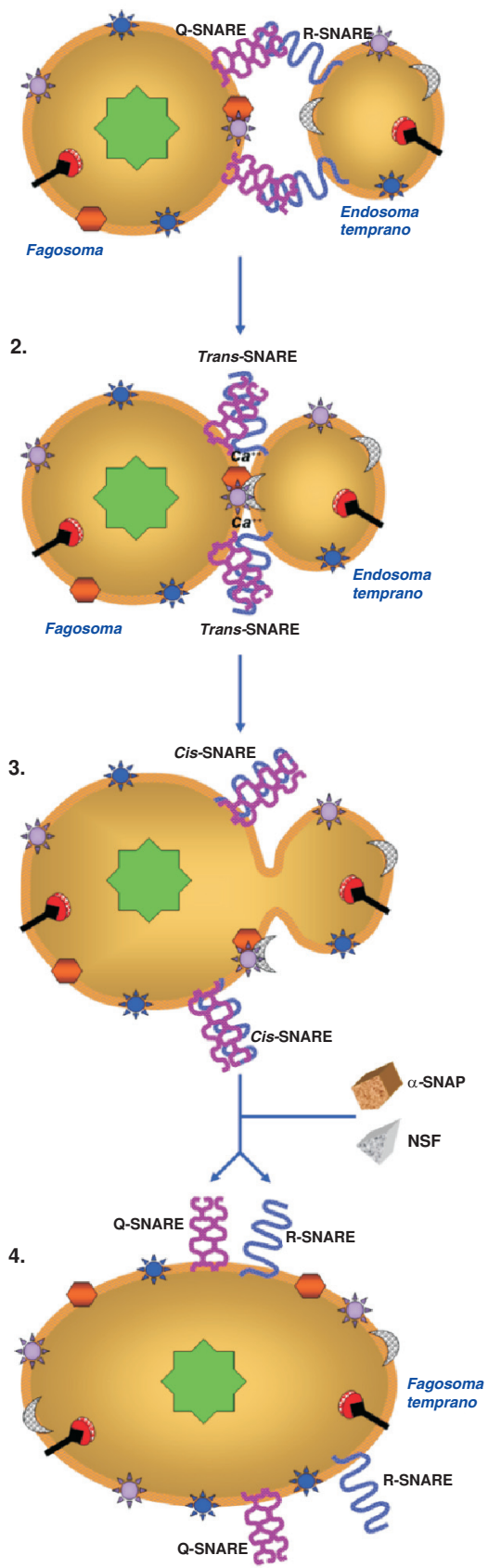

Figura 4. Esquema en el que se propone cómo sería la participación de las proteínas SNARE en la maduración de los fagosomas. 1. La R-SNARE presente en un endosoma temprano reconoce y se une a su correspondiente Q-SNARE en el fagosoma blanco. 2. Esta interacción forma los complejos trans-SNARE, los cuales acercan a las membranas favoreciendo la interacción del EEA-1 con PI(3)P y Rab5, y junto con el $\mathrm{Ca}^{2+}$ median la fusión de las membranas opuestas. 3. Luego de la fusión, las trans-SNARE que quedan en la membrana blanco reciben el nombre de cis-SNARE. 4. Finalmente, estas proteínas se separan en R-SNARE y Q-SNARE mediante la acción de $\alpha$-SNAP y NSF. Para mayor claridad ver convenciones de las figuras 1 y 2. vesículas a su membrana blanco (Rab1, Rab5) y la fusión de membranas mediante la regulación de proteínas como las SNARE $(32,33)$.

Las Rab tienen un plegamiento similar a las pequeñas GTPasas de la superfamilia de Ras, poseen seis hojas $\beta$ plegadas rodeadas de cinco hélices a y un sitio de unión al $\mathrm{Mg}^{2+}$ y a nucleótidos de guanina, que se encuentran en el lugar de interacción entre las hélices a y las hojas $\beta$ (33).

Las diferentes Rab se localizan en la cara del citosol de membranas intracelulares (de vesículas y organelas). Sin embargo, para que una proteína Rab se inserte en una membrana, debe sufrir modificaciones en su porción carboxi-terminal, en uno o dos motivos de cisteína, mediante la unión covalente de grupos hidrofóbicos isoprenil conocidos como geranil-genaril.

Esta reacción es catalizada por la geranil-geranil transferasa que reconoce el complejo integrado por una Rab recién sintetizada unida a una proteína REP (Rab Escort Protein). En general, el tránsito y la localización de cada proteína Rab depende de las modificaciones lipídicas que proveen un punto de anclaje a la membrana y de la región carboxiterminal de las Rab que, posiblemente, contiene señales de localización subcelular $(8,34)$. Se ha descrito que el reclutamiento de las Rab también depende del contenido de fosfolípidos -como el $\mathrm{PI}(3) \mathrm{P}, \mathrm{PI}(4,5) \mathrm{P}_{2}$ y $\mathrm{PI}(3,4,5) \mathrm{P}_{3}$ - y de la carga de estas membranas blanco $(35,36)$.

Las Rab recién sintetizadas que han recibido la modificación lipídica, son transportadas a su respectiva membrana por REP y en el caso de las Rab recicladas, por un inhibidor disociador del GDP, elGDI(GuanosineNucleotideDissociation Inhibitor). La REP y el GDI se encuentran estructuralmente relacionados, tienen gran preferencia por la Rab unida al GDP y cumplen un papel importante en la asociación reversible de estas proteínas con sus membranas respectivas. Sin embargo, a diferencia de la REP, el GDI no puede mediar la modificación lipídica de Rab descrita anteriormente. Para la activación de Rab, los factores de desplazamiento de GDI o REP median la disociación de Rab de estos complejos y permiten su interacción con la membrana respectiva $(34,37)$. Las Rab inactivas en las membranas son unidas y extraídas por el GDI. Estos complejos permanecen en el citosol en espera de otro ciclo de transporte.

La asociación de las Rab a las diferentes membranas está acompañada por el intercambio 
de un nucleótido de guanina. Las proteínas Rab funcionan haciendo ciclos entre un estado inactivo, unidas al GDP, y otro activo unidas al GTP (figura 5). El proceso de intercambio del nucleótido de guanina permite que las Rab estabilicen su interacción con la membrana blanco $(33,37)$.

Tanto Rab como Ras y Rho, otras GTPasas pequeñas, son poco eficientes para intercambiar 0 hidrolizar sus nucleótidos. Dos clases de proteínas regulan a las Rab positiva y negativamente: los GEF (Guanine Nucleotide Exchange Factors), que participan en la activación mediando el intercambio de GDP por GTP y las proteínas GAP (GTPasa Activating Protein), que inactivan las Rab al hidrolizar el GTP. Las GAP no muestran especificidad absoluta por sus sustratos, como la GAPCenA que interactúa con las Rab 6, 4 y 2. Las GAP tienen otras funciones como proteínas efectoras de las Rab e interactuando con otros componentes celulares como los miembros de la familia Rho $(8,33)$.

Como se mencionó anteriormente, mientras las formas inactivas de Rab se unen a REP o a GDI, las formas activas se unen a proteínas efectoras corriente abajo. Los efectores de Rab son proteínas que responden específicamente a las Rab activas y median, al menos, un efecto corriente abajo (37). Estas proteínas efectoras tienen secuencias y estructuras muy variables, como son las SNARE que facilitan eventos de fusión, proteínas que previenen la hidrólisis rápida del GTP y proteínas motoras que se asocian con el citoesqueleto (actina y tubulina) involucradas en el movimiento de vesículas.

Esta última función toma cada vez mayor protagonismo, ya que al parecer las Rab regulan el reclutamiento de proteínas motoras. Por ejemplo, la Rab6 interactúa con las cinesinas (38) que se mueven a lo largo de microtúbulos, dando soporte al desarrollo de la mitosis y la meiosis; la Rab27 regula el reclutamiento del motor de miosina Va basado en actina, el cual se encarga del transporte de melanosomas (39).

Una sola Rab puede tener más de una proteína efectora. Se han descrito 22 proteínas diferentes que pueden unir a Rab5-GTP y, de ellas, sólo cuatro se han identificado como factores específicos de Rab5 (rabaptina5, EEA1, rabenosina y PI3K) (32). Cada Rab señaliza por medio de una variedad de proteínas efectoras que actúan juntas para traducir la señal de una proteína Rab a diversos blancos del transporte de membranas, lo que indica que cada

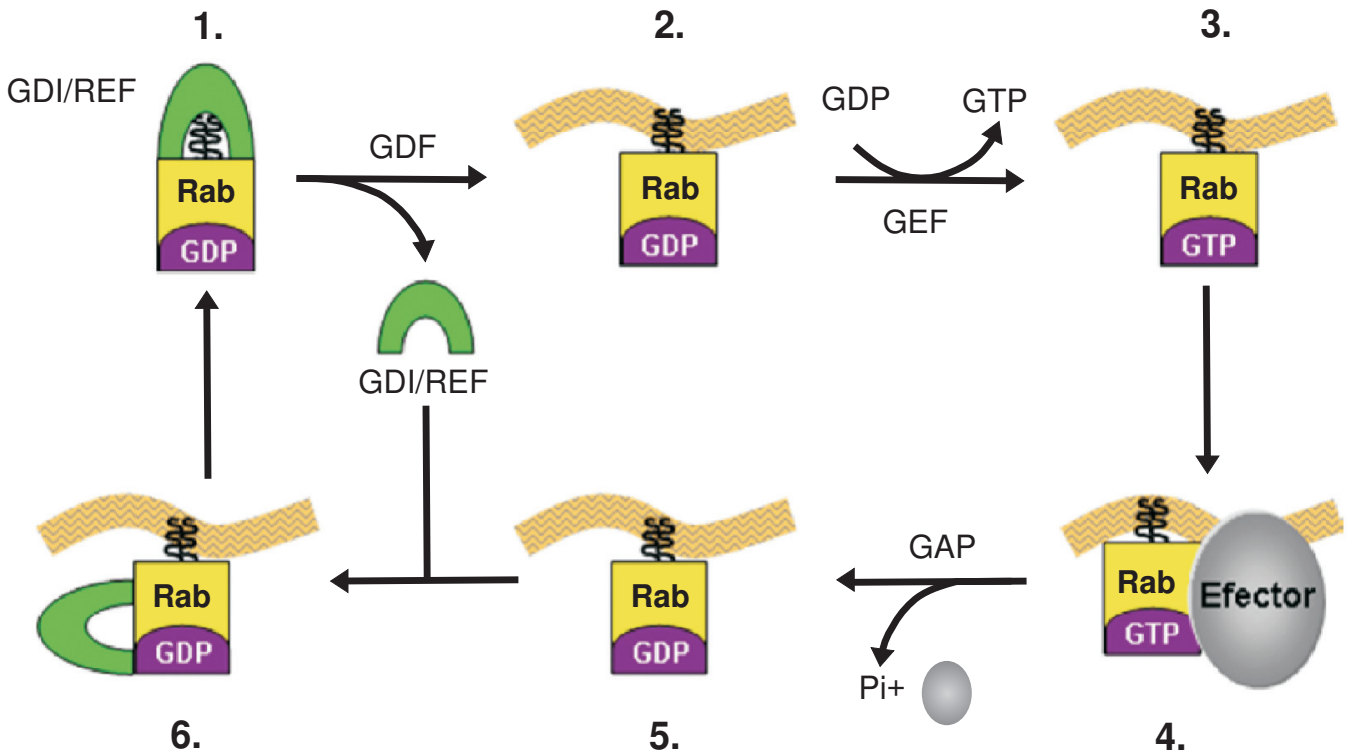

Figura 5. Ciclo de activación y desactivación de las Rab. 1. Las proteínas Rab que se encuentran unidas a GDP forman un complejo citosólico con GDI o con REF, dependiendo de si las Rab son recicladas o recién sintetizadas, respectivamente. 2. La entrega a la membrana blanco y la separación de GDI/REF de la proteína Rab son mediadas por un factor de desplazamiento de GDI (GDF). 3. La activación de Rab ocurre por intercambio del nucleótido catalizado por una GEF. 4. En estado activo, las proteínas Rab reclutan diferentes proteínas efectoras. 5. La Rab vuelve a su estado inactivo luego de la hidrólisis del GTP a GDP mediado por una GAP. 6. Una Rab en estado inactivo es reconocida y extraída de la membrana por GDI. 
Rab puede regular múltiples eventos moleculares en una sola región de la membrana. Sin embargo, aún se desconoce mucho de las proteínas efectoras de Rab en los mamíferos y de los mecanismos que éstas desencadenan.

\section{Alteraciones de la expresión y activación de las Rab durante la infección micobacteriana}

Las células del sistema inmunitario necesitan de la endocitosis y la vía secretoria para la ejecución de sus respuestas, como la fagocitosis y la secreción de citocinas. Se sabe que los patógenos pueden ser reconocidos y fagocitados por macrófagos, los cuales activan mecanismos efectores para su contención y eventual destrucción $(10,14)$. Sin embargo, algunos microorganismos del género Mycobacterium, como M. tuberculosis y M. bovis, pueden activar mecanismos de muerte celular con efectos fisiológicamente opuestos: la necrosis y la apoptosis (40).

Durante la infección in vitro de monocitos de pacientes con tuberculosis, se observan células necróticas y apoptóticas, mientras que en los monocitos de los individuos sanos, se encuentran esencialmente células apoptóticas (41). Se ha determinado que la apoptosis contribuye al control del crecimiento de $M$. tuberculosis y la necrosis favorece tanto su supervivencia como su diseminación (42). Además, Mycobacterium spp. inhibe tempranamente la acidificación de los fagosomas que lo contienen, escapando de los mecanismos bactericidas que poseen estas células, evadiendo el sistema inmunitario y sobreviviendo dentro del huésped (43).

Como se evidencia en ensayos realizados en nuestro grupo (figura 6A), mediante la marcación de los compartimientos ácidos de macrófagos derivados de monocitos humanos con la sonda comercial LysotrackerMR, hemos comprobado que en presencia de $M$. tuberculosis H37Rv vivo hay menor acidificación de los fagosomas que lo contienen, mientras las bacterias muertas, que no inhiben la maduración fagosómica, tienen mayor captación de la sonda acidotrópica (figura 6A).

Además de colonizar estos compartimentos no degradantes, las micobacterias vivas también escapan de los fagosomas al citosol ( $M$. tuberculosis, M. marinum y M. leprae) y, al parecer, la inhibición de la maduración fagolisosómica es un requisito para dicho escape $(44,45)$. Por lo tanto, la falta de acumulación del Lysotracker ${ }^{\mathrm{MR}}$ en los fagosomas que contienen la bacteria viva puede deberse, además de las razones expuestas anteriormente, a que algunas de ellas hayan escapado el citoplasma. Para solucionar este cuestionamiento nos proponemos implementar estudios por microscopía electrónica que permitan resolver en detalle la estructura del fagosoma.

M. tuberculosis puede alterar el ciclo de reclutamiento y activación de las Rab por los fagosomas, lo que explica en parte la inhibición de la maduración de los fagosomas micobacterianos (46). Se han reportado, principalmente, alteraciones de Rab5 y Rab7, pero también de otras como Rab4, Rab9, Rab11, Rab14 y Rab22a, que a continuación se explicarán en detalle.

\section{Generalidades de Rab5}

Las interacciones transitorias entre vesículas endocíticas son reguladas inicialmente por Rab5. Esta GTPasa se encuentra presente en la membrana plasmática, en endosomas y fagosomas tempranos $y$, aparentemente, está ausente en endosomas tardíos, en los cuales se localiza Rab7.

La Rab5 regula la formación y el tránsito de endosomas tempranos. Se han caracterizado tres isoformas de Rab5 (a, b y c) con una distribución subcelular y una regulación homóloga del tránsito vesicular $(47,48)$. Los fagosomas tempranos, que contienen partículas inertes, adquieren marcadores como el receptor de transferrina y la Rab5. Durante la maduración de los compartimentos, se pierde la expresión de estos marcadores y se adquieren unos de endosomas tardíos y lisosomas, como las LAMP (lysosome-associated membrane protein).

Se han estudiado las modificaciones y la maduración de los fagosomas en macrófagos de ratón J-774 expuestos a perlas de látex, mediante la separación de estos compartimentos sobre gradientes de sucrosa y su posterior análisis bioquímico. Esto ha permitido determinar que los fagosomas adquieren y pierdenvarios marcadores durantesu transformación a fagolisosomas. La expresión de Rab5 disminuye continuamente desde la primera hora de fagocitosis, mientras que aumenta la de la Rab7. Luego de 20 horas, ni Rab5 ni Rab7 se encuentran en estos fagosomas, lo que posiblemente indica que los compartimentos mas tardíos pierden la expresión de ambas GTPasas (49).

La detección y el seguimiento de la Rab5 y de sus diferentes isoformas ex vivo son técnicamente difíciles. Los niveles endógenos de Rab5 en células epiteliales y fibroblastos son bajos comparados 


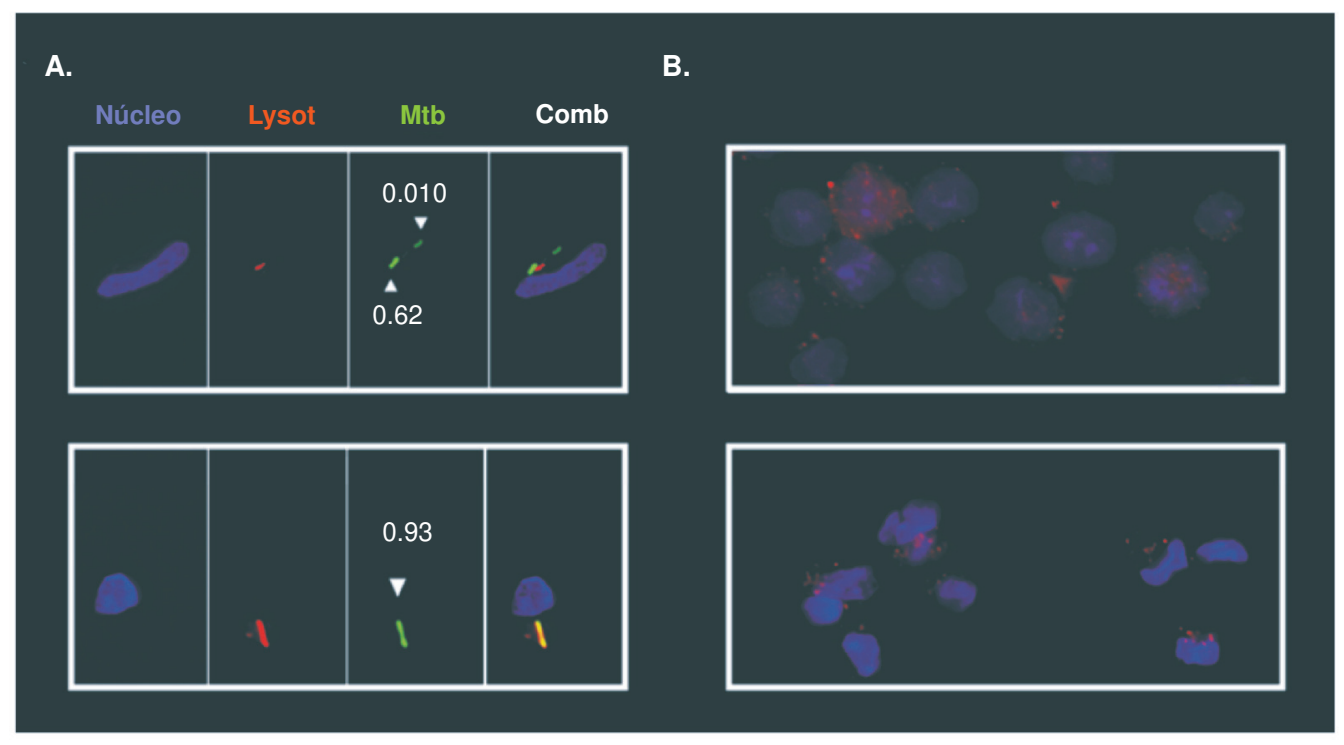

Figura 6. A. M. tuberculosis vivo y virulento inhibe la maduración de los fagosomas que lo contienen. Microscopía de epifluorescencia de macrófagos derivados de monocitos humanos infectados con M. tuberculosis (Mtb) vivo (arriba) y muerto (abajo) marcados con un derivado de la fluoresceína (verde). La infección se hizo por dos horas a $37^{\circ} \mathrm{C}$, se lavaron las bacterias extracelulares y se incubaron en las mismas condiciones por cuatro horas adicionales en presencia de la sonda comercial Lysotracker ${ }^{\mathrm{MR}}$ (rojo), que se acumula en los compartimientos ácidos y se considera un indicador de maduración de los fagosomas. Los números corresponden a los análisis de correlación entre la fluorescencia roja y la verde. Las micobacterias vivas permanecen preferencialmente en compartimentos no ácidos, mientras los fagosomas que contienen bacterias muertas lo hacen en mayor proporción.

B. Expresión de Rab5 en macrófagos humanos y de ratón. Inmunodetección de Rab5 (rojo) en la línea celular de ratón B10R (arriba) y en macrófagos derivados de monocitos humanos (abajo). Comb = superposición de las imágenes. Las fotos de $\mathbf{A}$ y $\mathbf{B}$ fueron tomadas en un microscopio Olympus Inverted IX81 con el objetivo 63X y el azul corresponde al ADN marcado con Hoescht 33258 (núcleo).

con la expresión en fagocitos mononucleares de humanos y de ratones (figura 6B).

Varios grupos han utilizado la estrategia de clonar formas silvestres y mutadas de Rab5 en diferentes líneas celulares para evaluar cambios en la función de las vesículas de una manera más eficiente. Se han definido mutantes de Rab5 constitutivamente activas, como la Q79L, que se encuentran principalmente acopladas a GTP por disminución tanto de su actividad GTPasa intrínseca como de la mediada por las GAP. Mientras que las mutantes dominantes negativas, como la S34N y N133l, tienen menor afinidad por GTP que por GDP y, por lo tanto, se encuentran principalmente unidas a GDP (50). El aumento de la expresión de la forma silvestre o las mutantes de Rab en líneas celulares, como la humana derivada del cáncer de cuello uterino HeLa y la de fibroblastos de riñón de hámster BHK-21, indica que la fusión entre endosomas tempranos requiere de la forma activa de Rab5, mientras las formas dominantes negativas inhiben dicha fusión. El aumento de la expresión de Rab5 silvestre aumenta la endocitosis y estimula la fusión entre endosomas tempranos $(47,51)$.
La Rab5 Q79L altera la morfología de endosomas tempranos en células BHK-21; se observa que, si bien estos compartimentos son positivos para el receptor de transferrina, las estructuras son más grandes que las observadas en células con aumento de la expresión de la Rab silvestre. Mediante un sistema no celular, se ha estudiado la fusión de endosomas tempranos provenientes de células que expresan formas silvestres o Q79L.

Los endosomas con las mutantes de Rab5 constitutivamente activas se fusionan de forma homóloga en mayor proporción, que los de células nativas, lo que se asocia con el aumento en el tamaño de los endosomas tempranos observado previamente (50). Este hallazgo ha sido ratificado mediante la utilización de Rab5 recombinante acoplada a una forma no hidrolizable de GTP $(\mathrm{GTP} \gamma \mathrm{S})(52)$.

El uso de dominantes negativas de Rab5 disminuye la endocitosis de receptores de transferrina, la fusión de endosomas tempranos e induce la fragmentación de estos compartimientos $(50,52)$. La transfección con una secuencia que codifica un inactivador de Rab5 como la RN-tre (una GAP), 
disminuye la incorporación de marcadores de endosomas tardíos como LAMP-1 y Rab7 (26). Estos resultados indican que se requiere Rab5 unida a GTP para la formación de endosomas tempranos y la fusión o asociación entre estos endosomas.

Sin embargo, las evidencias sobre la función de la Rab5 son controversiales. Se ha observado que la expresión de Rab5 Q79L en macrófagos de ratón RAW264.7 induce la formación de endosomas gigantes que, además de expresar marcadores de endosomas tempranos (EEA-1 y rabaptin-5), también expresan marcadores de endosomas tardíos (Rab7, LAMP-1 y LAMP-2), lo que demuestra un defecto más complejo en el fenotipo de estos endosomas gigantes.

No obstante, los estudios de microscopía electrónica muestran que estos endosomas no se asocian con lisosomas (53). De esta forma, a pesar de requerirse la activación de Rab5 para los eventos de fusión homotípica de endosomas tempranos y la fusión de fagosomas con estos endosomas, las anormalidades observadas con las formas constitutivamente activas de Rab5 (alteraciones en la morfología y expresión de marcadores de endosomas tardíos en estos compartimientos) resaltan la importancia de la actividad GTPasa de Rab5 para regular los eventos de fisión de estos fagosomas y endosomas.

Cuando las RAW264.7 se exponen al mismo tiempo a mezclas de dextrán con dos conjugados fluorescentes distintos (unas con verde y otras con rojo) dentro de los primeros 30 minutos de su interiorización, se evidencian ambas moléculas fluorescentes en los mismos compartimentos. A lo largo del tiempo (hasta 120 minutos), algunas de estas moléculas se ubican en vesículas diferentes, lo que demuestra la existencia de eventos de fisión endosómica. En las células que expresan Rab5 Q79L, ambas moléculas de dextrán se localizan simultáneamente por tiempos más prolongados (240 minutos), lo cual indica que la actividad GTPasa de Rab5 regula en alguna medida la fisión endosómica (53).

La Rab5 es reclutada rápida y transitoriamente sobre los fagosomas, lo que parece ser esencial para la maduración de estos compartimientos; sin embargo, se desconocen los mecanismos y las señales que llevan a la asociación de Rab5. Se ha postulado que la Rab5 media la fusión de estos fagosomas con endosomas tempranos mediante la unión con sus proteínas efectoras, como el EEA-1, el cual contiene dos dominios de unión a Rab5 y un dominio de interacción con $\mathrm{PI}(3) \mathrm{P}$.

En células RAW264.7 y de epitelio de ovario de hámster chino $\mathrm{CHO}$-IIA, transfectadas transitoriamente con la secuencia que codifica Rab5 silvestre acoplada a la proteína verde fluorescente (GFP), se observa que las células expuestas a perlas con opsonización con IgG y tratadas con un inhibidor irreversible de PI3K (Wortmannin), la Rab5 se mantiene asociada a los fagosomas por periodos más prolongados que los de las células que no tenían el inhibidor.

El proceso de maduración de estas vesículas se detiene en etapas tempranas, ya que estos compartimentos no se fusionan con endosomas tardíos. Se observa que la Rab5 continúa activa en estos compartimentos a pesar de la inhibición de la PI3K y, además, a pesar de la ausencia de $\mathrm{PI}(3)$ $P$, solamente se detectó una disminución parcial en el EEA-1 unido a fagosomas, lo que indica que esta proteína logra unir a la Rab5 activa, aun en ausencia de este fosfolípido.

Además, con fin de probar si la Rab5 unido a GTP es reclutada sobre fagosomas de células con inhibición de la PI3K, se han hecho ensayos de FRAP (Fluorescente Recovery after Photobleaching) por microscopía confocal, evaluando fagosomas de perlas de látex en células CHO-IIA transfectadas con Rab5 silvestre o con una forma constitutivamente activa acopladas a GFP, y tratados con Wortmannin o sin tratar. Para esto, extinguieron la fluorescencia del GFP de la Rab5 de unos fagosomas seleccionados mediante la exposición a un láser de alto poder y, posteriormente, siguieron estos compartimentos en el tiempo para determinar si los fagosomas recobraban o no la fluorescencia. Esto sólo se logra cuando estos compartimientos se unen a otros endosomas que no hayan perdido la fluorescencia de Rab5.

Se observó que los fagosomas con Rab5 silvestre recuperaron más rápidamente su fluorescencia que los que contenían la forma constitutivamente activa o la forma silvestre tratada con Wortmannin. Estos resultados indican que la capacidad de desactivación de Rab5, es decir, la disociación de Rab5 de los fagosomas cuando se hidroliza el GTP, es importante para permitir que los compartimentos maduren $y$, al parecer, esta disociación está asociada con la actividad de la PI3K (26). 
Los fagosomas nacientes contienen pequeñas cantidades de Rab5; luego, más Rab5 es reclutada sobre estos compartimentos mediante la fusión con endosomas tempranos. Si se inhibe la PI3K, se previene la disociación de Rab5 de los fagosomas. A pesar de esto, la Rab7 puede ser adquirida por estos compartimentos, posiblemente de la reserva del citosol, de una forma independiente de la PI3K. Deben existir, por lo tanto, dos señales para la fusión con estos endosomas tardíos: una dependiente de las Rab y otra dependiente de la PI3K (26).

En diferentes aproximaciones y modelos experimentales se ha definido, al igual que con la red endosómica, que la Rab5 participa en la formación y en la maduración de fagosomas. Empleando macrófagos RAW264.7, se ha determinado que la Rab5a no es reclutada, pero sí la F-actina, durante la formación de la vacuola fagocítica que contiene eritrocitos con opsonización con lgG; luego de cuatro minutos, se observa el cierre del fagosoma, se evidencia la despolimerización de la actina y, simultáneamente, el reclutamiento de Rab5 por el fagosoma (54).

Utilizando la tecnología FRET (Fluorescente Resonant Energy Transfer) y un modelo de fagocitosis de cuerpos apoptóticos en fibroblastos Swiss3T3 que expresan establemente la integrina $a_{v} \beta_{3}$, se determinó que la activación de Rab5 en la membrana de los fagosomas se inicia con el desensamble de la actina de estos compartimientos y es dependiente de Gapex-5, una GEF. Se observó que los fagosomas que contienen cuerpos apoptóticos conservan la expresión de Rab5 hasta por 10 minutos $y$, posteriormente, se pierde la expresión de esta GTPasa y estos compartimientos adquieren características de endosomas tardíos. Se ha encontrado que la expresión de una dominante negativa de Rab5 inhibe la maduración de los fagosomas en estas células (55).

En contraste, en macrófagos RAW264.7 transfectados con una mutante constitutivamente activa de Rab5, los fagosomas que contienen perlas de látex o Leishmania donovani son gigantes debido a un incremento en la fusión de fagosomas con endosomas tempranos. A pesar de que estos compartimientos expresan proteínas de endosomas tardíos, como LAMP-1, no maduraron a compartimientos hidrolíticos (56).

Los estudios de fagosomas microbianos han demostrado que los patógenos intracelulares, a diferencia de los extracelulares, regulan activamente el reclutamiento y estado de activación de las
Rab5. Salmonella typhimurium viva, en contraste con la muerta, recluta y retiene a Rab5 en los compartimientos vesiculares que la contienen, activando y, posiblemente promoviendo, la fusión de estas vesículas con endosomas tempranos e inhibiendo su transporte hacia lisosomas (57).

A diferencia de lo que se ha reportado para Mycobacterium spp., la infección con Listeria monocytogenes de células $\mathrm{CHO}$ establemente transfectadas con las formas silvestre y mutantes de Rab5, ha mostrado que estos patógenos intracelulares inhiben el recambio del nucleótido GDP de la Rab5, conservándolo en un estado inactivo, lo que además se asocia con baja actividad bactericida por parte de estas células. Además, el aumento de la expresión de mutantes de Rab5 constitutivamente activas incrementa la actividad microbicida de estas células, mientras la mutante dominante negativa, aumenta la supervivencia de las bacterias (58).

Los fagosomas que contienen el patógeno extracelular Staphylococcus aureus reclutan la GTPasa Rab5a en los primeros 5 minutos, y 30 minutos después de la fagocitosis diminuye significativamente su expresión. En este tiempo se observa la fusión de estos fagosomas con los gránulos azurófilos de neutrófilos humanos que tienen un alto contenido de enzimas lisosómicas (59).

Estos resultados demuestran la participación de la Rab5 en la maduración de los fagosomas tempranos e indican cómo diferentes patógenos intracelulares, además de M. tuberculosis -el cual se describe en detalle a continuación-modulan el reclutamiento y la activación de estas GTPasas.

\section{Los fagosomas que contienen Mycobacterium spp. retienen Rab5 unida a GTP.}

Desde la década de los 70 , se ha reportado la capacidad limitada de los fagosomas de fusionarse con lisosomas en presencia de micobacterias $(60,61)$. A finales de los 90 , se empezó a asociar este problema con la expresión y función de las Rab (62). A partir de macrófagos de ratón J-774 infectados con $M$. bovis BCG marcado con GFP o tratados con perlas de látex, se aislaron los fagosomas sobre gradientes de sucrosa y se midió el contenido de proteínas unidoras de GTP mediante ensayos de unión a [a- ${ }^{32}$ P]GTP. Los fagosomas que contenían $M$. bovis BCG (MPC) adquirieron y retuvieron a Rab5 y al receptor de transferrina, pero no a Rab4 que es propio de los 
endosomas de reciclamiento; tampoco adquirieron a Rab7 ni a LAMP-2, propios de endosomas tardíos, aun siete días después de la infección. Los fagosomas que contenían perlas de látex (LBC) reclutaron Rab7 y LAMP-2 luego de la primera hora de fagocitosis (62).

En células HeLa transfectadas con la secuencia que codifica para la isoforma silvestre de Rab5c, la infección con $M$. tuberculosis Erdman vivo e inactivado por calor, y en presencia de perlas de látex, mostró que la mayoría de fagosomas que contenían $M$. tuberculosis vivo eran positivos para Rab5 a las dos horas de fagocitosis y hasta dos días después; mientras que los fagosomas que contenían la micobacteria muerta y las perlas tuvieron baja expresión de Rab5 a los mismos tiempos. Este fenómeno se encontró también en células tratadas al mismo tiempo con $M$. tuberculosis vivo y las perlas.

Estos resultados indican que los fagosomas que contienen la micobacteria viva retienen a Rab5 en su membrana y no maduran a compartimientos endosómicos tardíos, a diferencia de lo que ocurre con los LBC o $M$. tuberculosis muerto. Además, la utilización de células que expresan la mutante constitutivamente activa de esta molécula (Q79L), evidencia un aumento en el tamaño de los endosomas tempranos y reclutamiento de LAMP-1, tanto en las células infectadas con $M$. tuberculosis como en las no infectadas. Por lo tanto, el cambio en los compartimentos que alojan la micobacteria en células que expresan la forma nativa versus la constitutivamente activa, hace pensar que los defectos en la maduración fagolisosómica observados durante la infección no se deben a la inhibición de la hidrólisis del GTP de Rab5 (63).

Estos resultados sugieren que el punto afectado en la maduración de los fagosomas de las micobacterias se encuentra en un estadio tan temprano como el de fagosomas Rab5 ${ }^{+}$Rab7 y que el evento molecular que se encuentra defectuoso en estas células es posterior o simultáneo al reclutamiento de Rab5.

A este respecto, se conocen varias proteínas efectoras que interactúan con Rab5 en los endosomas tempranos, algunas de las cuales han sido caracterizadas y parecen cumplir un papel importante en la regulación del tránsito endosómico, como: la rabaptina-5, proteína estabilizadora de Rab-GTP; la tuberina, una GAP; el rabex 5, una GEF y el EEA-1, que participa en interacciones complejas con miembros de la familia SNARE.
La expresión de estas proteínas se ha estudiado en los LBC y los MPC de células J-774. Se ha observado que a diferencia de los LBC, los cuales reclutan transitoriamente a EEA-1 con un pico de expresión entre los 10 y 20 minutos, los fagosomas que contienen $M$. bovis BCG no reclutan cantidades detectables de éste. En ninguno de estos fagosomas a los diferentes tiempos evaluados detecta rabaptina-5 ni tuberina. Cuando se compara la expresión de la SNARE sintaxina 13 y de los factores inactivadores de ésta (NSF y a-SNAP), no se encuentran diferencias entre LBC y MCP, lo que indica que el principal defecto es la exclusión de la proteína efectora de Rab5: EEA-1.

En contraposición con otros resultados (26), se ha observado que el bloqueo de la función de PI3K con Wortmannin y LY94002 previene significativamente la adquisición de EEA-1 en las endomembranas de los LBC; sin embargo, cuando se purifican los fagosomas y se evalúa directamente la expresión de la PI3K tipo III hVPS34, se encuentra que tanto los LBC como los MCP reclutan esta cinasa, aunque los MCP lo hacen más tempranamente. Esto sugiere, finalmente, la necesidad de VPS34 y Rab5 en el reclutamiento de EEA-1. Además, se ya que la PI3K es reclutada sobre los fagosomas micobacterianos, se considera que el efecto de la infección en esta enzima debe ser en su función.

Finalmente, en macrófagos de ratón tratados con perlas de látex recubiertas con fosfatidilinositol manósido (PIM) aislado de M. tuberculosis H37Rv o con un derivado de PIM con exceso de manosa, el lipoarabinomanan manosilado (ManLAM), se observó que el ManLAM, pero no el PIM, inhibe el reclutamiento del EEA-1 y del marcador tardío de endosomas, el ácido lisobifosfatídico (LBPA), por estos fagosomas.

Se concluye que el ManLAM es parcialmente responsable de la inhibición del reclutamiento de EEA-1, por mecanismos que no son completamente claros (64). Sin embargo, posiblemente involucran la función de la PI3K o los revestimientos de manosa que posee el ManLAM, los cuales pueden ser reconocidos por el receptor de manosa e inhibir directamente la maduración del fagosoma (65).

Estos investigadores también han demostrado que los MPC o los fagosomas que contienen perlas de látex recubiertas con ManLAM expresan las proteínas SNARE sintaxina 3, 8 y 13 de forma similar a los LBC, pero no adquieren componentes importantes en el transporte entre la red trans- 
Golgi y la vía endocítica, como el Rab9 y la sintaxina 6 (66).

Además, se ha reportado que la cellubrevina (67), una v-SNARE implicada en el tráfico desde el trans-Golgi hacia los endosomas mediante interacciones con la sintaxina 6 , se encuentra en dos formas en los MPC, una silvestre y otra de menor peso molecular. Al parecer, esta última se genera por un proceso de degradación proteica inducida por la infección y de la cual se desconocen sus implicaciones biológicas. Esto sugiere que el bloqueo en la maduración de estos fagosomas micobacterianos se debe a un problema en la adquisición directa de componentes desde el aparato de Golgi, como la bomba de protones ATPasa $(66,67)$. Los defectos en la regulación de estas proteínas efectoras de Rab podrían tener una influencia en la interrupción de la maduración de los fagosomas que contienen la micobacteria y podrían ser el resultado de alteraciones descritas en la función de las Rab durante la infección.

Se ha estudiado cómo los ciclos GTPasa de Rab5 alteran el cese de la maduración de fagosomas que contienen $M$. avium. Para esto han empleado macrófagos de ratón primarios derivados de médula ósea transducidos con la forma silvestre, la constitutivamente activa (Q79L) o la dominante negativa (S34N) de Rab5; los infectaron con $M$. avium 101 marcado con isocianato de fluoresceína y se ha encontrado que, prácticamente, todos los fagosomas de la micobacteria son positivos para Rab5, mientras sólo $20 \%$ de ellos son positivos para Rab7, 48 horas después de la infección.

Se observa una diferencia significativa en la expresión de la mutante Q79L versus S34N en los fagosomas que contienen las micobacterias, encontrando menor porcentaje de localización de la micobacteria con la forma dominante negativa de Rab unida a GDP y disminución de la fusión de endosomas tempranos. Se observa que, si bien las mutantes constitutivamente activas no tienen mayores alteraciones en la retención de $M$. avium en fagosomas tempranos, la forma dominante negativa induce disminución de marcadores propios de endosomas tempranos como el receptor de transferrina, un aumento significativo en la localización simultáneamente con marcadores de endosomas tardíos y lisosomas como LAMP1, LAMP2, y un incremento en el control de la replicación micobacteriana.

Estos resultados indican que, para que las micobacterias permanezcan en un fagosoma temprano, es indipensable que Rab5 esté unido a GTP o se encuentre constitutivamente activo. Además, se ha determinado que el tratamiento de estas células con citrato de hierro, pero no el hierro acoplado a transferrina, disminuye la maduración de los fagosomas que expresan la mutante S34N (68). Esto sugiere que la expresión de Rab5 S34N incrementa el transporte de $M$. avium a endosomas tardíos y lisosomas, posiblemente asociado con la limitada adquisición de hierro en estos compartimentos y, por lo tanto, indican que la actividad metabólica de estas bacterias es necesaria para que los compartimentos que contienen la micobacteria tengan un fenotipo temprano.

Es de notarse que el estudio de fagosomas que contienen $M$. tuberculosis aislados de neutrófilos humanos, mediante separación sobre gradientes de sucrosa y evaluación por Western blot, muestra que estos compartimentos expresan transferrina así como Rab5 unido a GTP y, a pesar de que se localizan simultáneamente con marcadores como LAMP-1, no lo hacen con enzimas lisosómicas como la mieloperoxidasa (59); de esta forma, a pesar de que los fagosomas que contienen a $M$. tuberculosis en los neutrófilos expresen Rab5 activo y no se localicen simultáneamente con enzimas lisosómicas, a diferencia de lo que ocurre en los monocitos y macrófagos, estas células logran destruir esta bacteria una vez es fagocitada. Posiblemente, esto es mediado por mecanismos efectores diferentes a la acción de enzimas hidrolíticas, como los dependientes de oxígeno y los componentes asociados con NET (Neutrophil Extracellular Traps) (69).

Comosemencionóanteriormente, existelahipótesis de que los defectos observados en la fusión fagolisosómica durante la infección micobacteriana se deben a la alteración en la función de la PI3K tipo III que llevaría a una disminución de los niveles de $\mathrm{PI}(3) \mathrm{P}$, lo que sería en parte responsable de la disminución en el acoplamiento de EEA-1.

Para comprobar esta hipótesis, se han transducido macrófagos de ratón derivados de médula ósea con la secuencia de la cinasa VPS34 o con la fosfatasa de $\mathrm{PI}(3) \mathrm{P}$ miotubularina (MTM1). Se ha comprobado que la PI3K es funcional en este modelo mediante la cuantificación de PI(3)P, empleando dos sondas fluorescentes conjugadas con los dominios peptídicos que reconocen este derivado fosforilado del fosfatidilinositol (FYVE y PX).

Al infectar con M. avium vivo las células transducidas con la cinasa, se observa que los fagosomas son 
positivos para $\mathrm{PI}(3) \mathrm{P}$ en mayor proporción que las transfectadas con la fosfatasa, y los cambios en las cantidades de $\mathrm{PI}(3) \mathrm{P}$ no tienen ninguna repercusión en la dinámica de maduración de los fagosomas micobacterianos.

Sin embargo, se observa un aumento de la maduración de los fagosomas que contienen M. avium muerta cuando los macrófagos son transducidos con VPS34 en comparación con MTM1 (70). Estos resultados concuerdan con los de otros estudios, que demuestran que en macrófagos de ratón derivados de médula ósea, la infección con $M$. tuberculosis induce la síntesis de $\mathrm{PI}(3) \mathrm{P}$, de manera más temprana que la observada con perlas de látex (15).

Existen, entonces, resultados contradictorios sobre el papel del $\mathrm{PI}(3) \mathrm{P}$ que, en general, parecen indicar que, si bien Mycobacterium spp. altera la cinética de producción de este fosfolípido, su permanencia en los fagosomas no resuelve las alteraciones descritas en la maduración de estos compartimientos. A pesar de esto, se considera como un efecto inductor de la maduración al aumento de $\mathrm{PI}(3) \mathrm{P}$ en los fagosomas que contienen la micobacteria muerta por calor en comparación con la micobacteria viva, la cual degrada constantemente el PI(3)P mediante la hidrólisis catalizada por la fosfatasa SapM (71). Además, se ha reportado que en las micobacterias sometidas a calor, el ManLAM, considerado uno de los factores inhibidores de EEA-1(64), sufre modificaciones estructurales que inducen la pérdida de su función (72).

Los estudios citados anteriormente demuestran que la persistencia de Rab5 activa en los fagosomas es una característica de la infección micobacteriana y, aunque no se conocen con claridad los mecanismos responsables de este hecho, probablemente sea un aspecto que mantiene a estos fagosomas con la capacidad de interactuar con endosomas tempranos y adquirir oligoelementos como el hierro. Además, esta activación persistente de Rab5 podría ser, en sí misma, un mecanismo que evite la maduración de los fagosomas. También, como se ha descrito para el ManLAM (65), Rab5-GTP u otras proteínas efectoras de Rab5 podrían tener algún papel directo en las alteraciones descritas sobre el reclutamiento de EEA-1.

\section{Generalidades de Rab7}

La Rab7 se encuentra, principalmente, en endosomas tardíos y está ausente en los tempranos (73). Mediante microscopía confocal, se ha determinado en células $\mathrm{CHO}$ que las GTPasas de endosomas tempranos como Rab4 y Rab5, así como marcadores como el receptor de transferrina, no se localizan simultáneamente con Rab7 (74).

En macrófagos de ratón J-774 tratados con perlas de látex, se demostró que la expresión de Rab5 disminuye continuamente luego de la primera hora de fagocitosis, al tiempo que aumenta la de Rab7, mediante la separación de estos compartimentos sobre gradientes de sucrosa (49). Estas evidencias han sugerido que Rab5 y Rab7 definen compartimentos endocíticos distintos y han servido de soporte a la hipótesis del proceso de recambio de las Rab, en el que la Rab7 aparece en la membrana luego de la desaparición de la Rab5.

Similar a lo que ocurre con la Rab5, los estudios realizados para Rab7 también emplean líneas celulares transfectadas con las secuencias que codifican la molécula silvestre, mutantes constitutivamente activas (como Q67L, 141M) $(75,76)$ o mutantes dominantes negativas (como T22N y N125I) (75). La transfección estable de Rab7 silvestre y la mutante Q67L en las líneas celulares BHK-21 y HeLa con posteriores análisis morfológicos y bioquímicos de su localización subcelular, demuestran que esta GTPasa se encuentra principalmente en estructuras endocíticas terminales, como endosomas tardíos y lisosomas $(75,76)$.

Además, similar a lo que ocurre con los endosomas tempranos cuando se evalúan mutantes de Rab5, el aumento de la expresión de Rab7 silvestre, o constitutivamente activa, incrementa el tamaño y la agregación perinuclear de los lisosomas; mientras que las mutantes dominantes negativas inducen acumulación de pequeñas vesículas lisosómicas en la periferia de las células $(75,77)$.

La evaluación de diferentes líneas celulares demuestra que la Rab7 constitutivamente activa se localiza simultáneamente con marcadores de endosomas tardíos y lisosomas como el LAMP-1 y LAMP-2 y en pocos casos con el receptor de manosa-6-fossfato (MPR) (75,76). Esto deja entrever que, si bien la Rab7 se expresa en un compartimiento conectado con lisosomas, es posible que represente un compartimiento en una etapa intermedia de maduración o que se trate de vesículas completamente diferentes de las que contienen el MPR que, a su vez, contribuyen a la maduración de estos compartimentos. 
Las señales que regulan el recambio de Rab5 por Rab7 no se conocen con exactitud, pero es claro que son parcialmente independientes de PI3K. Los fagosomas de las líneas celulares RAW264.7 y CHO-IIA, transfectadas transitoriamente con la secuencia que codifica para Rab7 y tratadas con Wortmannin, aunque en menor proporción que las células no tratadas, reclutan y activan a Rab7 y, además, se observa la presencia de RILP (Rab7Interacting Lysosomal Protein), proteína efectora de Rab7 en estos compartimentos. Además, cuando se evalúan las células transfectadas con una mutante de Rab7 constitutivamente activa, se observa que ésta, así como el Wortmannin, no interfieren con la adquisición de marcadores de endosomas tardíos y lisosomas como el LAMP-1, lo que refuerza el hecho de que la PI3K es dispensable para la activación de la Rab7 (26).

Los primeros estudios que evaluaron la función de Rab7 muestran que ésta cumple un papel en la regulación del tránsito endocítico ulterior a Rab5, específicamente en la maduración y organización de endosomas tardíos $(75,78,79)$. Se ha evaluado la interiorización y maduración de compartimientos que contienen la proteína $\mathrm{G}$ del virus de estomatitis vesicular en células BHK-21, las cuales tienen un aumento de la expresión la proteína Rab7 silvestre - diferentes mutantes dominantes negativas (N125I y T22N). Se observa que el aumento de la expresión de la forma silvestre permite su transporte hasta endosomas tardíos y su posterior degradación, mientras que la mutante negativa induce su acumulación en compartimentos endocíticos tempranos que expresan el receptor de transferrina y su procesamiento proteolítico disminuye hasta en un $50 \%$ (78).

Posteriormente, se comprobó que la Rab7 regula el transporte y la fusión de endosomas tardíos con lisosomas (77). En células HeLa que expresan Rab7 silvestre o mutada acopladas a la proteína EGFP (Enhanced GFP) y mediante microscopía confocal y electrónica, se encuentra que la Rab7 se expresa en estructuras endocíticas tardías, principalmente, en lisosomas. Las formas mutantes negativas de Rab7 (T22N y N125I) hacen que ésta se exprese en el citosol y no se asocie a membranas y, además, hacen que lipoproteínas de baja densidad ingeridas no tengan acceso a componentes de lisosomas como la catepsina $D$ y el LAMP-1, y hacen que estos compartimentos presenten una acidificación reducida (77). De esta forma, se ha demostrado el papel de la Rab7 en la maduración de compartimentos a estructuras endocíticas tardías y su posterior fusión con lisosomas.

Se ha comprobado que la regulación del transporte a compartimentos degradantes por parte de Rab7 se hace mediante RILP $(80,81)$. La RILP es una proteína de $45 \mathrm{kDa}$ expresada principalmente en el citosol y es la única proteína efectora caracterizada hasta el momento de Rab7 (80). Mediante el uso del sistema de doble híbrido en levaduras y de precipitaciones simultáneas, se ha demostrado que la RILP se une por medio de su porción carboxi-terminal y de forma específica con Rab7GTP $(80,81)$.

Los estudios in vivo en los que se emplearon células HeLa transfectadas con la forma silvestre y mutantes constitutivamente activas y dominante negativas de Rab7, demostraron que la RILP es reclutada a las membranas de endosomas tardíos y lisosomas (se localiza simultáneamente con LAMP-1 y catepsina D) y se observa que la asociación con estos compartimentos aumenta con la expresión de una mutante constitutivamente activa de Rab7, pero no cuando la dominante negativa está presente (80). Además, se observa que el aumento de la expresión de RILP restaura las alteraciones morfológicas observadas en los compartimentos tardíos en células con la mutante dominante negativa de Rab7; también, se encontró que una mutante de RILP que pierda su porción carboxi-terminal inhibe la maduración de endosomas tempranos de forma comparable a lo observado con las mutantes negativas de Rab7 (80). Estos resultados indican que la RILP es clave en la maduración y el transporte a compartimentos degradantes.

En RILP se ha caracterizado un dominio homólogo a las cadenas pesadas de las colas de miosina, involucrado en la movilización asociada a microtúbulos (80). Además, se ha observado que en células Mel JuSo (melanoma humano) que expresan RILP, esta proteína se ubica en endosomas tardíos y lisosomas alrededor del MTOC (Microtubule-Organizing Center) (81).

Se ha demostrado que en los lisosomas de células que expresan la forma silvestre de RILP, a diferencia de lo que ocurre con una mutante que pierda la porción amino-terminal, estos compartimientos expresan diferentes complejos motores acoplados a microtúbulos y asociados con el trasporte vesicular, como la dinactina y cinesina (81). Sin embargo, ellos no han encontrado que la RILP pueda interactuar directamente con el 
motor de la dinactina del citoesqueleto. Tenemos, entonces, que la porción N-terminal de la RILP se requiere para el reclutamiento del complejo dineinadinactina, mientras que la porción C-terminal es indispensable para su interacción con la Rab7 activa. Estos resultados sugieren que la RILP induce el reclutamiento del complejo dineinadinactina por los endosomas tardíos y lisosomas, induciendo el transporte de estos compartimentos por los microtúbulos hacia el MTOC.

Otroestudio(82), enelqueseemplearon macrofágos de ratón RAW264.7 transfectados con las formas silvestres o mutadas de Rab-7 (T22N y Q67L) y RILP, muestra resultados que están de acuerdo con estas observaciones. En estas células, a las que se les han marcado las estructuras endosómicas tardías con un conjugado de dextrán-Texas red, se observa que el reclutamiento de Rab7 por los fagosomas con perlas de látex precede su fusión con endosomas tardíos y lisosomas, así como su desplazamiento hacia el centro de la célula. Además, se observa que RILP se recluta sólo por los fagosomas cuando se expresa la mutante constitutivamente activa de Rab7, mas no cuando la mutante dominante negativa está presente.

Cuando se emplea una mutante de RILP truncada en su porción amino terminal, se observa que, a pesar de reclutarse por los fagosomas, éstos no se fusionan ni con endosomas tardíos ni con lisosomas, y pierden su movimiento centrípeto, mediado por el complejo motor dineina-dinactina.

Finalmente, se observó que la RILP favorece la formación de unos túbulos que protruyen desde el fagosoma hasta el endosoma tardío y lisosomas, induciendo la fusión con estas estructuras (82). Se concluye que el complejo Rab7-RILP es importante para la fusión de los fagosomas con estructuras endosómicas tardías y lisosomas, así como para su desplazamiento hacia el MTOC.

Se ha determinado que en fagosomas de eritrocitos con opsonización con lgG, la Rab7 se expresa desde los 9 minutos hasta, al menos, 6 horas después de la fagocitosis. Estos fagosomas pueden expresar simultáneamente y por breves periodos (entre los 5 y 7,5 minutos), tanto Rab5 como Rab7. En este mismo estudio, también se determinó que LAMP1 tiene una cinética de reclutamiento por estos fagosomas completamente diferente a Rab7, lo que sugiere que estas moléculas llegan al fagosoma por medio de vías y vesículas diferentes (54).
El estudio de la maduración de los fagosomas que contienen $E$. coli ha permitido determinar que esta bacteria evade la respuesta inmunitaria de macrófagos peritoneales de ratones infantes (dos semanas de vida) en comparación con células provenientes de ratones adultos (seis semanas). Esto se asocia con un bajo reclutamiento de Rab7 por el fagosoma, con una baja actividad microbicida por parte de estas células y con defectos en la acidificación de los fagosomas que contienen $E$. coli (83).

Además, se ha propuesto que para Leishmania spp. la inhibición de la maduración fagolisosómica es importante para el cambio de promastigotes a amastigotes. Empleando macrófagos de ratón $\mathrm{J}-774$, se ha reportado que los fagosomas que contienen $L$. donovani deficiente del factor de virulencia lipofosfoglucano, se fusionan en altas proporciones con endosomas y maduran a fagolisosomas, adquiriendo marcadores como EEA1, receptor de transferrina, LAMP1 y Rab7. Mientras que los fagosomas que contienen $L$. donovani silvestre no adquieren Rab7, aunque reclutan LAMP1 con una cinética más retardada que las mutantes deficientes del lipofosfoglucano (84).

Estos resultados sugieren que el reclutamiento de Rab7, más que la adquisición de LAMP-1 por los fagosomas, es un punto crítico en la completa maduración de esos compartimientos; igualmente, se logran apreciar los mecanismos que utilizan algunos microorganismos para evitar dicha maduración de una forma dependiente de la modulación de Rab7.

\section{Los fagosomas que contienen Mycobacterium spp. tienen una menor expresión de Rab7.}

Como ya se ha mencionado a lo largo de este texto, décadas atrás se había definido que los compartimientos que contienen $M$. tuberculosis tienen una fusión limitada con los lisosomas de su célula huésped. Sin embargo, el primer reporte conocido que involucra a Rab7 en este proceso se describe en la década de los 90, cuando se aislaron fagosomas que contenían $M$. bovis BCG o perlas de látex a partir de macrófagos de ratón J-774 sobre gradientes de sucrosa. Encontraron que, mientras los fagosomas LBC expresaron altas cantidades de Rab5, Rab7 y LAMP-2 durante la primera hora después de la fagocitosis, éstas disminuyen hacia las 168 horas; los fagosomas MPC tienen una baja expresión de Rab5 a la primera hora y aumenta hacia las 168 horas. La expresión de Rab7 en 
los MCP fue muy baja o indetectable durante los tiempos estudiados (62). Estos resultados sugieren que los fagosomas MCP tienen un bloqueo en la maduración en estadios tempranos caracterizados por la presencia de Rab5, los cuales no logran avanzar a estadios más tardíos determinados por la expresión y acumulación de Rab7.

Durante varios años existió debate en cuanto a si los fagosomas MCP expresan Rab7 o si no lo hacen. Estudios más recientes señalan que, efectivamente, esta GTPasa está presente en los fagosomas micobacterianos (85). La infección con M. tuberculosis de células HeLa con expresión estable de las formas de Rab7 silvestre, mutantes constitutivamente activas (Q67L) o deficientes en su actividad GTPasa, evidencian por microscopía electrónica que los fagosomas micobacterianos adquieren Rab7 silvestre constitutivamente activa; sin embargo, a pesar de expresar esta GTPasa, los compartimientos presentan una maduración alterada, ya que tuvieron muy bajas cantidades de LAMP-1. Se concluyó que la inhibición en la maduración de los fagosomas micobacterianos no puede atribuirse a defectos en la adquisición de Rab7, lo que indica que este bloqueo debe encontrarse en un paso posterior o simultáneo a la adquisición de esta enzima.

Se ha investigado (68) cómo los ciclos de GTPasa de Rab5 y Rab7 modulan la maduración del fagosoma de M. avium. Para esto, se han empleado macrófagos de ratón transducidos con la forma silvestre, la constitutivamente activa (Q67L) o la dominante negativa (S22N) de Rab7; los infectan con $M$. avium 101 marcado con FITC y se evalúan por microscopía confocal. Se ha encontrado que la mayoría de los fagosomas micobacterianos adquieren Rab5, mientras sólo, aproximadamente, $20 \%$ de ellos expresan Rab7. No se observaron diferencias en la marcación con Rab7 o en la maduración de los fagosomas micobacterianos (positividad para receptor de transferrina y LAMP-1) dependiente de la isoforma empleada de esta GTPasa. Estos resultados demuestran que, a diferencia de lo observado con Rab5, la presencia de Rab7 constitutivamente activa o dominante negativa no induce la maduración de los fagosomas micobacterianos, lo cual indica que el bloqueo en los fagosomas MCP no se debe al estado de activación de esta enzima.

En otro estudio (86), la línea celular monocítica THP-1 fue marcada con una sonda fluorescente para los fagosomas que contenían perlas de látex, en presencia de BSA (control) o de fracciones solubles provenientes de lisados totales de $M$. tuberculosis o M. smegmatis. Luego de 2 horas, se aislaron los fagosomas, se permeabilizaron y marcaron para detectar Rab7 y LAMP-1 mediante citometría de flujo. Se observó disminución en la adquisición de estos marcadores de endosomas tardíos por los fagosomas de las células tratadas con los lisados totales de $M$. tuberculosis, comparados con el control y con la micobacteria de crecimiento rápido. En general, los resultados de estos estudios sugieren que Rab7 se recluta sobre los fagosomas micobacterianos. Sin embargo, comparativamente el porcentaje de expresión y el número de moléculas por fagosoma parece ser menor.

Con el estudio de la cinética de expresión y localización espacial de Rab7 en los fagosomas de M. tuberculosis en macrófagos RAW264.7, se ha encontrado que esta GTPasa es reclutada transitoriamente por los fagosomas que contienen la micobacteria viva y, posteriormente, es liberada por mecanismos desconocidos. Se ha encontrado que la mayoría de los fagosomas que contienen la micobacteria expresan LAMP-2 de una forma independiente de Rab7, mientras que la localización de la catepsina $D$ en estos compartimientos depende de esta GTPasa.

Por lo tanto, la disociación de Rab7 de los fagosomas micobacterianos puede ser una de las causas del bloqueo en la maduración de estos fagosomas (artículo en impresión. Seto $\mathrm{S}$, et al. Dissection of Rab7 localization on Mycobacterium tuberculosis phagosome, Biochem Biophys Res Commun. 2009. Doi:10.1016/j.bbrc.2009.06.152). Estos resultados apoyan la hipótesis mencionada anteriormente que sugiere que la maduración de los fagosomas se lleva a cabo, al menos, por dos vías diferentes que permiten la adquisición de los componentes característicos de endosomas tardíos y lisosomas.

El estudio de células J-774A.1 y RAW264.7 con aumento de la expressión de RILP silvestre transfectan con las mutantes constitutivamente activas (Q67L) y dominantes negativas (T22N), demuestran que Rab7 se acopla a fagosomas de perlas de látex y de $M$. bovis BCG vivo independientemente de su estado de activación. La interacción de RILP con Rab7 ocurre en fagosomas con perlas de látex y $M$. bovis BCG inactivada con gentamicina. En estos compartimientos predomina la forma Rab7-GTP, que es significativamente 
reducida en los fagosomas de $M$. bovis BCG vivo, los cuales presentan Rab7-GDP. Esto indica que RILP se recluta, principalmente, por los fagosomas que contienen la forma activa de Rab7. Estos resultados se asocian con una actividad GTPasa de Rab7 detectada en los filtrados de sobrenadantes de cultivo de $M$. bovis BCG y $M$. tuberculosis H37Rv, y no de M. smegmatis (87).

\section{Otras Rab durante la infección micobacteriana}

Los trabajos aludidos anteriormente evidencian que la maduración de los fagosomas micobacterianos se detiene entre los estadios controlados por Rab5 y Rab7; más recientemente, se ha demostrado la participación de otras GTPasas en el bloqueo de la maduración de estos compartimientos, como Rab6, Rab9, Rab11, Rab14 y Rab22. Debido a que $M$. tuberculosis permanece por largos periodos dentro de fagosomas de fagocitos y estos compartimentos se caracterizan por ser estructuras dinámicas y que reciben constantemente nutrientes, algunos investigadores han estudiado si otras Rab, además de Rab5, podrían estar involucradas en este proceso.

La Rab11 regula el reciclamiento de receptores desde endosomas tempranos hasta la superficie celular; además, media el tránsito de proteínas, como el receptor de tranferrina, desde endosomas perinucleares hacia la membrana plasmática $(88,89)$. En fagocitos mononucleares se ha observado que Rab11 participa en la fusión de endosomas con la membrana plasmática durante la fagocitosis, hecho que permite al macrófago disponer de una mayor área de superficie celular para la interiorización eficiente de agentes foráneos (90).

El estudio de las vacuolas que contienen $M$. tuberculosis H37Rv en macrófagos derivados de monocitos humanos, ha permitido observar que éstos ni se acidifican, ni se fusionan con endosomas tardíos (expresión del MPR), pero acumulan Rab11 en sus membranas. Luego de 5 días de infección, $45 \%$ a $65 \%$ de los fagosomas micobacterianos retuvieron la expresión de esta GTPasa; este hallazgo se ha asociado con acceso de los compartimentos a la vía de reciclaje y a nutrientes (expresión de transferrina), y se ha encontrado que estos fagosomas tienen además acceso a la vía biosintética (expresión de proteínas específicas del RE, calnexina y Grp78/BiP) y comunicación con la vía endocítica (mediante la adquisición de dextrán). Asimismo, estos macrófagos son permisivos para la replicación micobacteriana (91).
Otro reporte también ha demostrado la expresión de Rab11 en fagosomas que contienen $M$. bovis BCG, empleando macrófagos de ratón (92).

En las células dendríticas derivadas de monocitos humanos infectadas con $M$. tuberculosis, no se observan ni acidificación ni fusión de endosomas tardíos con lisosomas como en macrófagos. Sin embargo, se ha encontrado que a las tres horas de infección sólo entre 10\% y $15 \%$ de los fagosomas micobacterianos expresan Rab11, tienen menos acceso a la vía biosintética (reclutamiento de proteínas específicas del retículo endoplásmico: calnexina y Grp78/BiP) y a nutrientes (expresión de transferrina), no hay replicación micobacteriana en estas células y logran activar linfocitos $T$ (91). Se sugiere que parte de la baja capacidad de replicación que tienen estas bacterias en células dendríticas comparadas con macrófagos, se debe a que las primeras restringen el acceso a nutrientes, mediante una reducida comunicación con la vía de reciclaje y biosintética, mientras en los macrófagos esto puede darse de forma continua, probablemente, por un efecto de Rab11.

La agrupación de las Rab de acuerdo con su topología ha permitido identificar ocho grupos posibles (I-VIII). Las proteínas pertenecientes a cada grupo tienen un alto grado de similitud en su secuencia de aminoácidos, lo cual se ha asociado con similitudes funcionales y de localización subcelular (31). Por esta razón, se ha estudiado en los fagosomas micobacterianos de macrófagos RAW264.7 la expresión de los miembros del grupo $\mathrm{V}$ al que pertenecen, además de la Rab5, las subfamilias Rab21 y Rab22a.

Mediante el uso de microscopía confocal se ha observado que los fagosomas que contienen BCG o perlas de látex siguen una cinética similar para la expresión de Rab21 y Rab5, mientras que se han encontrado diferencias significativas en el reclutamiento de Rab22a en estos fagosomas. Se ha hallado que los fagosomas con $M$. tuberculosis vivo reclutan tempranamente y retienen la expresión de Rab22a en sus membranas, al menos durante el tiempo evaluado (3.000 segundos). Los macrófagos a los cuales se les ha silenciado la expresión de Rab22a mediante ARN de interferencia, han tenido mayor maduración de los compartimentos que contienen M. tuberculosis vivo y han aumentado la expresión de Rab7, mientras que los macrófagos que sobre-expresan la mutante dominante negativa (Q64L), han detenido la maduración de los fagosomas con M. tuberculosis muertas. Estos 
autores sugieren que la detención en la maduración fagolisosómica, así como la adquisición de Rab7 por parte de los fagosomas micobacterianos, dependen de Rab22a, y que éste podría ser un punto crítico para la conversión de Rab7 y en el avance hacia compartimentos endosómicos tardíos (93). Por lo tanto, durante la infección micobacteriana, los fagosomas en los que se encuentra la bacteria reclutan grandes cantidades de Rab22a, lo que previene la maduración fagolisosómica.

La Rab14 se localiza en la vía biosintética y de reciclaje entre el aparato de Golgi y compartimentos endosómicos en la línea celular HeLa y en células de riñón de rata (94), pero, en macrófagos de ratón, se asocia principalmente con endosomas tempranos y participa en la fusión de estos compartimentos con fagosomas y en la fusión homotípica entre fagosomas (95). El seguimiento de la expresión de Rab14 silvestre acoplada a EGFP en los fagosomas que contenían $M$. bovis BCG viva o muerta, han permitido observar que esta GTPasa se recluta tempranamente luego de la fagocitosis y se acumula en mayor proporción en los fagosomas que contienen la micobacteria viva en comparación con los que contienen la muerta. Los compartimentos con la micobacteria viva mantienen este aumento de la expresión durante 50 minutos, mientras la expresión de Rab14 en la mayoría de los fagosomas que contenían el bacilo muerto fue solamente transitoria (menos de cinco minutos).

La importancia de Rab14 en el bloqueo de la maduración de estos compartimentos se ha estudiado en macrófagos deficientes en la expresión de esta molécula, mediante el uso de un ARN de silenciamiento o de líneas celulares que expresan la mutante dominante negativa (S25N y N125I) de esta GTPasa. Con estas condiciones, se ha encontrado que los fagosomas que contienen la micobacteria maduran a compartimentos ácidos e hidrolíticos; mientras que el aumento de la expresión de la isoforma de Rab14 silvestre o la mutante activada constitutivamente (Q70L) previenen la maduración fagolisosómica en los compartimentos que contienen la micobacteria muerta (95). Por lo tanto, se concluye que la Rab14 juega un papel en la inhibición de la fusión fagolisosómica durante la infección micobacteriana y se postula que esta GTPasa contribuye al mantenimiento de estos fagosomas en un estadio inmaduro mediante fusión continua de estos compartimientos con endosomas tempranos.
La expresión de otras Rab también se encuentra comprometida en los fagosomas micobacterianos, como es el caso de la Rab9, la cual, al igual que Rab7, seasociaprincipalmenteconcompartimientos endocíticos tardíos. Esta Rab participa en el tránsito de proteínas desde la red trans-Golgi y tiene un papel en el reciclamiento del MPR $(96,97)$. A diferencia de lo que ocurre con perlas de látex, se ha observado ausencia en la expresión de Rab9 en las fagosomas que contienen $M$. tuberculosis luego de una y 24 horas de infección (66). Además, estos resultados se relacionan con la ausencia de reclutamiento de la SNARE sintaxina 6 (66) y Rab6 (91) por los fagosomas micobacterianos, las cuales también participan en el tránsito vesicular entre el trans-Golgi y la vía endocítica. Estos resultados sugieren que existe una alteración en la comunicación directa entre los compartimentos que contienen la micobacteria y la vía biosintética de la células y, que ésta podría corresponder a una vía simultánea de maduración de los fagosomas.

\section{Panorama general y perspectivas}

Al comparar el tránsito de otras organelas endocíticas y exocíticas, el papel de las Rab en el transporte de los fagosomas es menos claro, pero el estudio de diversos modelos celulares como la infección micobacteriana, ha permitido dilucidar la participación de diferentes Rab en este sistema y ha permitido definir alteraciones en la expresión, activación y recambio de estas GTPasas durante la infección de fagocitos mononucleares.

En resumen, se ha observado que los fagosomas micobacterianos retienen la expresión de GTPasas activas características de endosomas tempranos y de reciclaje, como son Rab5, Rab22a, Rab14 y Rab11. También, se observa ausencia o baja expresión de GTPasas de endosomas tardíos y de vesículas provenientes de la vía biosintética, como Rab7, Rab9 y Rab6 (figura 7). Este fenotipo se ha asociado con la adaptación de las bacterias al nicho intracelular, la modulación e inhibición de la maduración de los fagosomas, haciéndolos compartimientos débilmente ácidos, no hidrolíticos, y previniendo la activación de los mecanismos efectores que llevan a su destrucción, pero, al mismo tiempo, teniendo acceso a nutrientes y oligoelementos esenciales para su metabolismo, replicación y probable escape al citoplasma.

Sin embargo, el panorama es complejo, ya que al analizar los resultados en conjunto es imposible clasificar a los fagosomas micobacterianos como estrictamente tempranos o como no tardíos, 
debido a que expresan marcadores de endosomas tempranos y de reciclaje pero, al mismo tiempo, dejan de expresar marcadores típicos de estos compartimientos, como el EEA-1, y pueden llegar a expresar moléculas de endosomas tardíos y lisosomas como Rab7 y LAMP-1 (figura 7).

Por lo tanto, los fagosomas micobacterianos corresponderían a compartimientos especializados acondicionados por la micobacteria y para ella, con comunicación con diferentes componentes de la vía endocítica, biosintética y de reciclaje, que presentan cierto grado de inmadurez porque tienen baja actividad hidrolítica. Para esto, la micobacteria debe controlar diferentes aspectos de la maduración del fagosoma y regular específicamente la adquisición de los elementos que conforman este compartimiento, como sería el reclutamiento directo de proteínas del citosol, la fusión parcial o total con endosomas de reciclaje, tempranos o tardíos, la adquisición de componentes provenientes directamente desde la vía endocítica y los complejos proteicos que son eliminados por eventos de fisión, entre otros.

A pesar de haberse definido un patrón de expresión y activación de algunas Rab en los fagosomas micobacterianos, aún es incierto si este fenotipo es el responsable de la inhibición en la maduración fagosómica o si es sólo una consecuencia de otros elementos operantes. Actualmente, se desconoce cómo la infección modula todo este sistema y no se han logrado definir los mecanismos exactos por los cuales la micobacteria altera la dinámica de expresión y activación de estas GTPasas. A diferencia de lo que ocurre con otras bacterias

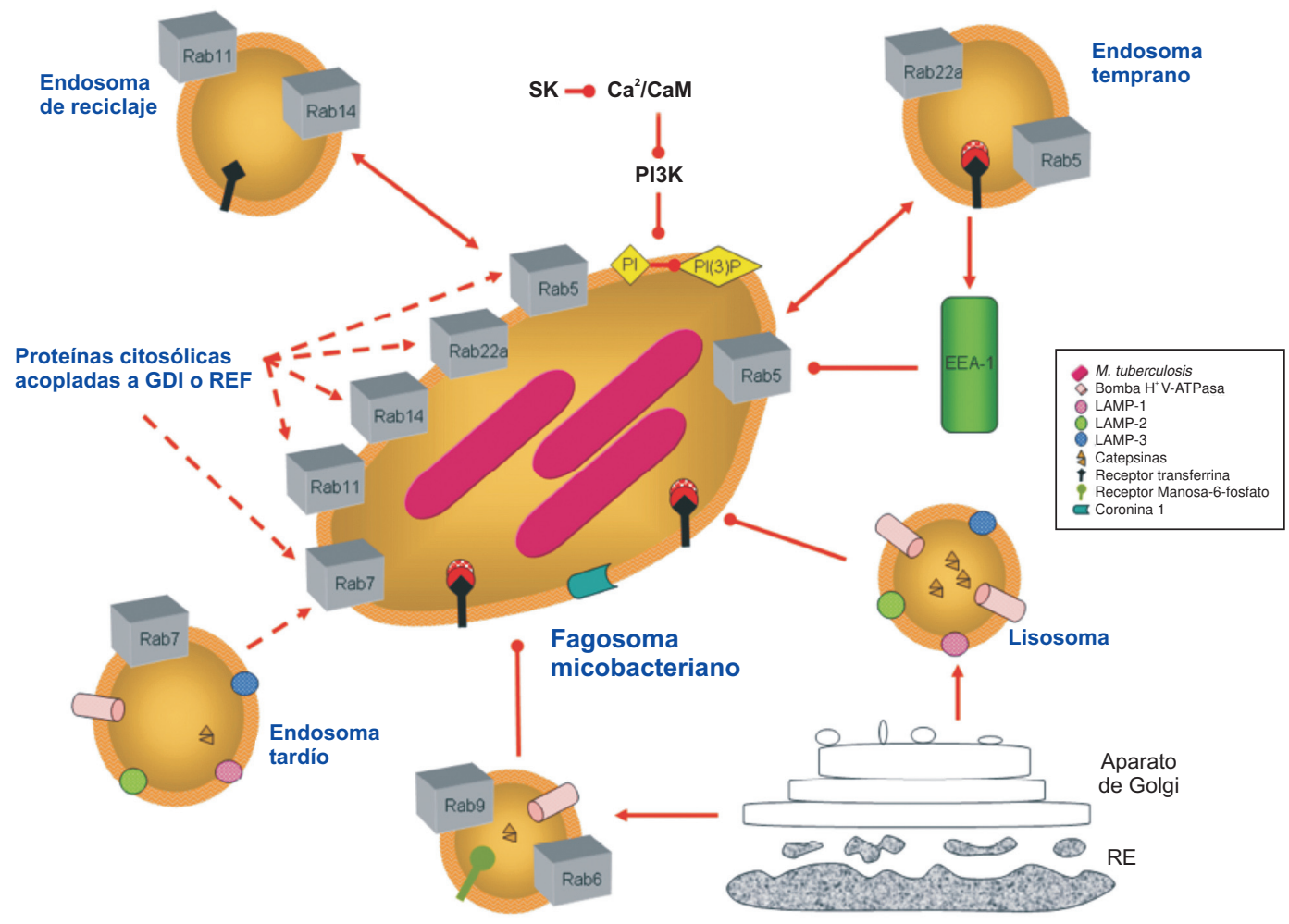

Figura 7. Esquema que propone cómo se espera que sea la expresión de las proteínas Rab en el fagosoma micobacteriano. Teniendo en cuenta el patrón de expresión de diferentes Rab y otras moléculas en los fagosomas que contienen M. tuberculosis, se postula que estos compartimientos tienen una comunicación aumentada y continúa con endosomas de reciclaje y endosomas tempranos (flecha con línea continua), exceptuando el acoplamiento del EEA-1 (línea con cabeza roma). También, se propone la hipótesis de que parte de las Rab que se expresan en estos fagosomas provienen del reclutamiento directo a partir del citoplasma (flecha con línea discontinua). Por otro lado, estos compartimientos tienen algún grado de comunicación con endosomas tardíos (flecha con línea discontinua), pero no lo tienen con lisosomas y vesículas con comunicación directa con la vía biosintética (línea con cabeza roma). Las alteraciones descritas en la vía de señalización acoplada al calcio (línea con cabeza roma) en los fagosomas micobacterianos tienen un papel bien establecido en la inhibición de la maduración fagolisosómica y pudieran estar participando, además, en las alteraciones observadas en el reclutamiento y activación de las Rab. 
como Legionella spp., con $M$. tuberculosis, a excepción del ManLAM, no se conocen factores de virulencia que afecten a las Rab o a sus proteínas efectoras. Por lo tanto, parte de los aspectos que se deben estudiar en el futuro son los componentes microbianos, factores liberados o productos del metabolismo micobacteriano que afecten directamente a las Rab, o a las proteínas reguladoras de la función de estas GTPasas, como son las REP, GDI, GEF y GAP.

Se ha descrito, como ocurre con Listeria spp. (98), que $M$. tuberculosis escapa del fagosoma al citosol en fagocitos mononucleares (45). Sin embargo, se desconocen los mecanismos moleculares que gobiernan dicho escape, así como la forma como se replica el bacilo en este sitio y cuál sería su implicación en la presentación cruzada de antígenos micobacterianos a los linfocitos T CD8+. El reclutamiento de las Rab por el fagosoma micobacteriano y su estado de activación podrían jugar un papel en la salida de las micobacterias al citosol, ya que la inhibición de la maduración fagolisosómica es un requisito para dicho escape (45).

Todavía se desconocen las vías de señalización implicadas en el reclutamiento y activación de las Rab por los fagosomas, las cuales podrían alterarse durante la infección con $M$. tuberculosis. Se ha postulado la existencia de diferentes factores de virulencia y enzimas liberadas por la micobacteria que modulan la maduración de los fagosomas y, para el caso particular de las Rab, parecen afectar más la capacidad de estas GTPasas de interactuar con sus proteínas efectoras, que alterar su propia incorporación a los fagosomas y su estado de activación. Por ejemplo, se ha caracterizado el defecto en el reclutamiento y función de proteínas que interactúan directamente con Rab5: la PI3K y el EEA-1. Se ha demostrado que el ManLAM de la pared de la micobacteria impide el reclutamiento de EEA-1 e inhibe la activación de la VPS34, porque altera entre otros el incremento en el calcio del citosol observado durante la fagocitosis $(64,66,99)$.

Debido a que no se cuenta con ratones deficientes de las Rab mencionadas en este artículo, se desconocen las implicaciones biológicas de las mismas en la infección micobacteriana in vivo, como son la supervivencia y replicación de la bacteria, la formación del granuloma y, la patogénesis y evolución de la enfermedad. Además, ya que la mayoría de los estudios funcionales de las Rab se han realizado en células transfectadas, se requiere de mesura al momento de interpretar los resultados, porque si bien las tranfecciones se consideran una aproximación válida al problema, su alcance se limita por el hecho de que los niveles de proteínas expresados no reflejan los fisiológicos de las células.

En los estudios más recientes de las diferentes Rab, los investigadores han sopesado parte de este problema, implementando otras metodologías, como el ARN de interferencia, que inhibe con cierta especificidad la expresión de la Rab seleccionada. Sin embargo, se debe tener en cuenta que estas aproximaciones experimentales son sistemas aún en desarrollo y, por lo tanto, todavía no se consideran métodos completamente eficientes y suficientemente validados.

Durante los últimos años no se les ha dado suficiente atención a los lípidos como reguladores de la fagocitosis y de la maduración de los fagosomas (100). Lípidos como los fosfoinositoles, la fosfatidilserina, el ácido fosfatídico y el colesterol, entre otros, son requeridos como sustratos y como activadores de enzimas responsables de la generación de segundos mensajeros. Se ha observado, por ejemplo, que fagosomas que contienen perlas de látex o eritrocitos opsonizados con IgG, presentes en macrófagos RAW264.7 tratados con un compuesto que bloquea la salida del colesterol de endosomas y lisosomas, tuvieron una maduración temprana normal, ya que reclutaron Rab5 y EEA1, pero no se asociaron con lisosomas ya que, a pesar de que se observó reclutamiento de Rab7, este permaneció en un estado inactivo (101).

El glucolípido de la micobacteria ManLAM, pero no el PIM, es en parte responsable de la inhibición de la maduración del fagosoma que contiene $M$. tuberculosis (65). Se ha observado que bacterias muertas por mecanismos que no alteran la conformación de la pared bacteriana y la estructura del ManLAM (como, por ejemplo, la radiación gamma) siguen inhibiendo dicha maduración (65). Teniendo en cuenta el alto contenido lipídico de la micobacteria y el hecho de que el contenido de lípidos del fagosoma puede afectar el reclutamiento, anclaje y recambio de las Rab, es importante reorientar los estudios en esta área para determinar si otros componentes lipídicos de la micobacteria, además del ManLAM, influencian directa o indirectamente la presencia de Rab en estos compartimientos. 
El panorama de lo que ocurre con estas GTPasas en los fagosomas en presencia de la micobacteria, podría estarse enmascarando por la heterogeneidad de las estrategias experimentales, dado que la mayoría de los estudios han evaluado la participación individual de las Rab durante la infección micobacteriana o lo han hecho empleando diferentes micobacterias, modelos celulares y tiempos de infección. Por lo tanto, se necesitan más estudios que evalúen al mismo tiempo la función, el estado de activación y el reclutamiento de diferentes Rab, cuando una de ellas es modificada o inactivada, con el fin de determinar si la alteración de una Rab que se asocie con los fagosomas tempranamente, cambia o altera la expresión o función de otras Rab.

Otro aspecto que se debe tener en cuenta es que cada fagosoma se considera una entidad única y la heterogeneidad de los fagosomas ha sido evidente en diversos estudios. Se conoce que según el receptor involucrado hay mecanismos diferenciales en términos de la capacidad efectora, es decir, la formación y maduración de estos compartimientos depende de la biología del receptor fagocítico, de la señal que éste traduzca, del rearreglo del citoesqueleto, del tránsito de membrana y del transporte de iones, entre otros (11). Desde el mismo reconocimiento, según los receptores involucrados, los fagosomas presentan heterogeneidad en diferentes componentes como las proteínas cinasas, fosfatasas, GTPasas y enzimas modificadoras de lípidos, entre otros. Por lo tanto, el patrón de expresión y activación de las Rab en los fagosomas micobacterianos podría estar difiriendo, dependiendo del receptor fagocítico empleado.

Teniendo en cuenta que más de 60 Rab han sido identificadas en los humanos, podrían existir más de estas enzimas, así como otras proteínas efectoras de Rab acopladas a los fagosomas, que podrían estar alteradas durante la infección micobacteriana. Por ejemplo, existen otras Rab de las que se tiene poca información funcional pero que se han asociado con las membranas fagosómicas y que todavía no se han estudiado en lo fagosomas micobacterianos, como son Rab3 y Rab10. Además, se han reportando alteraciones de otras Rab, principalmente disminución de la expresión de Rab33a, en linfocitos $T$ de pacientes con tuberculosis comparados con controles sanos (102). Esto sugiere que el efecto de la infección sobre estas GPTasas no se restringe sólo a los fagosomas o a los fagocitos mononucleares, siendo posiblemente un efecto sistémico más de la infección.

El estudio continuo de cómo patógenos, como $M$. tuberculosis, regulan el reclutamiento o exclusión de las Rab, es clave para el entendimiento completo de las vías de tránsito celular que gobiernan la fagocitosis. Igualmente, el entendimiento de los mecanismos utilizados por las micobacterias para perturbar el ciclo de activación de las Rab es indispensable para comprender mejor la fisiopatología de esta infección, y para utilizarse como blancos putativos en el desarrollo de nuevos fármacos con potencial efecto antituberculoso.

\section{Agradecimientos}

Agradecimientos a Patricia Cardona, del Grupo de Neurociencias de la Sede de Investigación Universitaria, Universidad de Antioquia, por su colaboración y soporte técnico en los montajes para microsocopía de fluorescencia.

\section{Conflicto de intereses}

Según el conocimiento de los autores, los resultados presentados en este trabajo no tienen ningún conflicto de interés.

\section{Financiación}

Esta revisión está enmarcada dentro del desarrollo del trabajo doctoral de Diana Castaño, quien ha sido beneficiaria de una beca del Programa de Doctorados Nacionales de COLCIENCAS y cuyo trabajo también ha sido financiado por dicha Institución con los Proyectos Código 111540520270 y con el Convenio para la Unión Temporal Contrato RC 431-2004.

\section{Referencias}

1. Malik ZA, Denning GM, Kusner DJ. Inhibition of $\mathrm{Ca}(2+)$ signaling by Mycobacterium tuberculosis is associated with reduced phagosome-lysosome fusion and increased survival within human macrophages. J Exp Med. 2000;191:287302.

2. Malik ZA, Thompson CR, Hashimi S, Porter B, lyer SS, Kusner DJ. Cutting edge: Mycobacterium tuberculosis blocks $\mathrm{Ca} 2+$ signaling and phagosome maturation in human macrophages via specific inhibition of sphingosine kinase. J Immunol. 2003;170:2811-5.

3. Roche PA. Intracellular protein traffic in lymphocytes: "how do I get THERE from HERE"? Immunity. 1999;11:391-8.

4. Kroemer G, Galluzzi L, Brenner C. Mitochondrial membrane permeabilization in cell death. Physiol Rev. 2007;87:99-163.

5. Armstrong C, Edwards R, Jan L, Kaback R, Kühlbrandt W, Miller C, et al. Intracellular vesicular traffic. In: Alberts B, Johnson A, Lewis J, Raff M, Roberts K, Walter P, editors. 
Molecular biology of the cell. Fourth edition. New York: Garland Science; 2002. p. 711-66.

6. Le Roy C, Wrana JL. Clathrin- and non-clathrin-mediated endocytic regulation of cell signalling. Nat Rev Mol Cell Biol. 2005;6:112-26.

7. Seaman MN. Membrane traffic in the secretory pathway: Endosome protein sorting: motifs and machinery. Cell Mol Life Sci. 2008;65:2842-58.

8. Grosshans BL, Ortiz D, Novick P. Rabs and their effectors: achieving specificity in membrane traffic. Proc Natl Acad Sci USA. 2006;103:11821-7.

9. Aderem A, Underhill DM. Mechanisms of phagocytosis in macrophages. Annu Rev Immunol. 1999;17:593-623.

10. Haas A. The phagosome: compartment with a license to kill. Traffic. 2007;8:311-30.

11. Vieira OV, Botelho RJ, Grinstein S. Phagosome maturation: aging gracefully. Biochem J. 2002;366:689-704.

12. Scott CC, Botelho RJ, Grinstein S. Phagosome maturation: a few bugs in the system. J Membr Biol. 2003;193:137-52.

13. Underhill DM, Ozinsky A. Phagocytosis of microbes: complexity in action. Annu Rev Immunol. 2002;20:825-52.

14. Clemens DL. Characterization of the Mycobacterium tuberculosis phagosome. Trends Microbiol. 1996;4:113-8.

15. Chua J, Deretic V. Mycobacterium tuberculosis reprograms waves of phosphatidylinositol 3-phosphate on phagosomal organelles. J Biol Chem. 2004;279:36982-92.

16. Kusner DJ. Mechanisms of mycobacterial persistence in tuberculosis. Clin Immunol. 2005;114:239-47.

17. Deretic V, Singh S, Master S, Harris J, Roberts E, Kyei G, et al. Mycobacterium tuberculosis inhibition of phagolysosome biogenesis and autophagy as a host defense mechanism. Cell Microbiol. 2006;8:719-27.

18. Spiegel S, Kolesnick R. Sphingosine 1-phosphate as a therapeutic agent. Leukemia. 2002;16:1596-602.

19. Yadav M, Clark L, Schorey JS. Macrophage's proinflammatory response to a mycobacterial infection is dependent on sphingosine kinase-mediated activation of phosphatidylinositol phospholipase $\mathrm{C}$, protein kinase $\mathrm{C}$, ERK1/2, and phosphatidylinositol 3-kinase. J Immunol. 2006;176:5494-503.

20. Colombo MI, Beron W, Stahl PD. Calmodulin regulates endosome fusion. J Biol Chem. 1997;272:7707-12.

21. Lindmo K, Stenmark H. Regulation of membrane traffic by phosphoinositide 3-kinases. J Cell Sci. 2006;119:605-14.

22. Deretic V, Fratti RA. Mycobacterium tuberculosis phagosome. Mol Microbiol. 1999;31:1603-9.

23. Chua J, Vergne I, Master S, Deretic V. A tale of two lipids: Mycobacterium tuberculosis phagosome maturation arrest. Curr Opin Microbiol. 2004;7:71-7.

24. Garin J, Diez R, Kieffer S, Dermine JF, Duclos S, Gagnon E, et al. The phagosome proteome: insight into phagosome functions. J Cell Biol. 2001;152:165-80.

25. Gagnon E, Duclos S, Rondeau C, Chevet E, Cameron PH, Steele-Mortimer O, et al. Endoplasmic reticulum-mediated phagocytosis is a mechanism of entry into macrophages. Cell. 2002;110:119-31.

26. Vieira OV, Bucci C, Harrison RE, Trimble WS, Lanzetti L, Gruenberg J, et al. Modulation of Rab5 and Rab7 recruitment to phagosomes by phosphatidylinositol 3-kinase. Mol Cell Biol. 2003;23:2501-14.

27. Stow JL, Manderson AP, Murray RZ. SNAREing immunity: the role of SNAREs in the immune system. Nat Rev Immunol. 2006;6:919-29.

28. Zhao C, Slevin JT, Whiteheart SW. Cellular functions of NSF: not just SNAPs and SNAREs. FEBS Lett. 2007;581:2140-9.

29. Hong W. Cytotoxic T lymphocyte exocytosis: bring on the SNAREs! Trends Cell Biol. 2005;15:644-50.

30. Leabu M. Membrane fusion in cells: molecular machinery and mechanisms. J Cell Mol Med. 2006;10:423-7.

31. Pereira-Leal JB, Seabra MC. Evolution of the Rab family of small GTP-binding proteins. J Mol Biol. 2001;313:889-901.

32. Zerial M, McBride H. Rab proteins as membrane organizers. Nat Rev Mol Cell Biol. 2001;2:107-17.

33. Stenmark H, Olkkonen VM. The Rab GTPase family. Genome Biol. 2001;2:3007.

34. Seabra MC, Wasmeier C. Controlling the location and activation of Rab GTPases. Curr Opin Cell Biol. 2004;16:451-7.

35. Heo WD, Inoue T, Park WS, Kim ML, Park BO, Wandless TJ, et al. $\mathrm{PI}(3,4,5) \mathrm{P} 3$ and $\mathrm{PI}(4,5) \mathrm{P} 2$ lipids target proteins with polybasic clusters to the plasma membrane. Science. 2006;314:1458-61.

36. Yeung T, Terebiznik M, Yu L, Silvius J, Abidi WM, Philips $\mathbf{M}$, et al. Receptor activation alters inner surface potential during phagocytosis. Science. 2006;313:347-51.

37. Segev N. Ypt and Rab GTPases: insight into functions through novel interactions. Curr Opin Cell Biol. 2001;13: 500-11.

38. Echard A, Jollivet F, Martinez O, Lacapere JJ, Rousselet A, Janoueix-Lerosey $\mathrm{I}$, et al. Interaction of a Golgi-associated kinesin-like protein with Rab6. Science. 1998;279:580-5.

39. Wu X, Rao K, Bowers MB, Copeland NG, Jenkins NA, Hammer JA 3rd. Rab27a enables myosin Va-dependent melanosome capture by recruiting the myosin to the organelle. J Cell Sci. 2001;114:1091-100.

40. Pan H, Yan BS, Rojas M, Shebzukhov YV, Zhou H, Kobzik $\mathrm{L}$, et al. Ipr1 gene mediates innate immunity to tuberculosis. Nature. 2005;434:767-72.

41. Gil DP, Leon LG, Correa LI, Maya JR, Paris SC, Garcia LF, et al. Differential induction of apoptosis and necrosis in monocytes from patients with tuberculosis and healthy control subjects. J Infect Dis. 2004;189:2120-8.

42. Arcila ML, Sánchez MD, Ortiz B, Barrera LF, García LF, Rojas M. Activation of apoptosis, but not necrosis, during Mycobacterium tuberculosis infection correlated with decreased bacterial growth: role of TNF-alpha, IL10, caspases and phospholipase A2. Cell Immunol. 2007;249:80-93. 
43. Vergne I, Chua J, Singh SB, Deretic V. Cell biology of Mycobacterium tuberculosis phagosome. Annu Rev Cell Dev Biol. 2004;20:367-94.

44. Stamm LM, Morisaki JH, Gao LY, Jeng RL, McDonald $\mathrm{KL}$, Roth R, et al. Mycobacterium marinum escapes from phagosomes and is propelled by actin-based motility. J Exp Med. 2003;198:1361-8.

45. van der Wel N, Hava D, Houben D, Fluitsma D, van Zon M, Pierson J, et al. M. tuberculosis and M. leprae translocate from the phagolysosome to the cytosol in myeloid cells. Cell. 2007;129:1287-98.

46. Brumell JH, Scidmore MA. Manipulation of Rab GTPase function by intracellular bacterial pathogens. Microbiol Mol Biol Rev. 2007;71:636-52.

47. Bucci C, Parton RG, Mather IH, Stunnenberg H, Simons K, Hoflack B, et al. The small GTPase rab5 functions as a regulatory factor in the early endocytic pathway. Cell. 1992;70:715-28.

48. Bucci C, Lutcke A, Steele-Mortimer O, Olkkonen VM, Dupree $\mathrm{P}$, Chiariello $\mathrm{M}$, et al. Co-operative regulation of endocytosis by three Rab5 isoforms. FEBS Lett. 1995;366:65-71.

49. Desjardins M, Huber LA, Parton RG, Griffiths G. Biogenesis of phagolysosomes proceeds through a sequential series of interactions with the endocytic apparatus. J Cell Biol. 1994;124:677-88.

50. Stenmark H, Parton RG, Steele-Mortimer O, Lutcke A, Gruenberg J, Zerial M. Inhibition of rab5 GTPase activity stimulates membrane fusion in endocytosis. Embo $\mathrm{J}$. 1994;13:1287-96.

51. Gorvel JP, Chavrier P, Zerial M, Gruenberg J. Rab5 controls early endosome fusion in vitro. Cell. 1991;64:91525.

52. Barbieri MA, Li G, Colombo MI, StahI PD. Rab5, an early acting endosomal GTPase, supports in vitroendosome fusion without GTP hydrolysis. J Biol Chem. 1994;269:18720-2.

53. Duclos S, Corsini R, Desjardins M. Remodeling of endosomes during lysosome biogenesis involves 'kiss and run' fusion events regulated by Rab5. J Cell Sci. 2003;116:907-18.

54. Henry RM, Hoppe AD, Joshi N, Swanson JA. The uniformity of phagosome maturation in macrophages. J Cell Biol. 2004;164:185-94.

55. Kitano M, Nakaya M, Nakamura T, Nagata S, Matsuda M. Imaging of Rab5 activity identifies essential regulators for phagosome maturation. Nature. 2008;453:241-5.

56. Duclos S, Diez R, Garin J, Papadopoulou B, Descoteaux A, Stenmark $\mathbf{H}$, et al. Rab5 regulates the kiss and run fusion between phagosomes and endosomes and the acquisition of phagosome leishmanicidal properties in RAW 264.7 macrophages. J Cell Sci. 2000;113:3531-41.

57. Mukherjee K, Siddiqi SA, Hashim S, Raje M, Basu SK, Mukhopadhyay A. Live Salmonella recruits $\mathrm{N}$-ethylmaleimide-sensitive fusion protein on phagosomal membrane and promotes fusion with early endosome. J Cell Biol. 2000;148:741-53.

58. Prada-Delgado A, Carrasco-Marín E, Pena-Macarro C, Del Cerro-Vadillo E, Fresno-Escudero M, Leyva-Cobian
F, et al. Inhibition of Rab5a exchange activity is a key step for Listeria monocytogenes survival. Traffic. 2005;6:252-65.

59. Perskvist N, Roberg K, Kulyte A, Stendahl O. Rab5a GTPase regulates fusion between pathogen-containing phagosomes and cytoplasmic organelles in human neutrophils. J Cell Sci. 2002;115:1321-30.

60. Hart PD, Armstrong JA, Brown CA, Draper P. Ultrastructural study of the behavior of macrophages toward parasitic mycobacteria. Infect Immun. 1972;5:803-7.

61. Hart PD, Armstrong JA. Strain virulence and the lysosomal response in macrophages infected with Mycobacterium tuberculosis. Infect Immun. 1974;10:742-6.

62. Via LE, Deretic D, Ulmer RJ, Hibler NS, Huber LA, Deretic V. Arrest of mycobacterial phagosome maturation is caused by a block in vesicle fusion between stages controlled by Rab5 and Rab7. J Biol Chem. 1997;272:13326-31.

63. Clemens DL, Lee BY, Horwitz MA. Deviant expression of Rab5 on phagosomes containing the intracellular pathogens Mycobacterium tuberculosis and Legionella pneumophila is associated with altered phagosomal fate. Infect Immun. 2000;68:2671-84

64. Fratti RA, Backer JM, Gruenberg J, Corvera S, Deretic V. Role of phosphatidylinositol 3-kinase and Rab5 effectors in phagosomal biogenesis and mycobacterial phagosome maturation arrest. J Cell Biol. 2001;154:631-44.

65. Shimada K, Takimoto H, Yano I, Kumazawa Y. Involvement of mannose receptor in glycopeptidolipid-mediated inhibition of phagosome-lysosome fusion. Microbiol Immunol. 2006;50:243-51.

66. Fratti RA, Chua J, Vergne I, Deretic V. Mycobacterium tuberculosis glycosylated phosphatidylinositol causes phagosome maturation arrest. Proc Natl Acad Sci USA. 2003;100:5437-42.

67. Fratti RA, Chua J, Deretic V. Cellubrevin alterations and Mycobacterium tuberculosis phagosome maturation arrest. J Biol Chem. 2002;277:17320-6.

68. Kelley VA, Schorey JS. Mycobacterium's arrest of phagosome maturation in macrophages requires Rab5 activity and accessibility to iron. Mol Biol Cell. 2003;14:3366-77.

69. Fuchs TA, Abed U, Goosmann C, Hurwitz R, Schulze I, Wahn V, et al. Novel cell death program leads to neutrophil extracellular traps. J Cell Biol. 2007;176:231-41.

70. Kelley VA, Schorey JS. Modulation of cellular phosphatidylinositol 3-phosphate levels in primary macrophages affects heat-killed but not viable Mycobacterium avium's transport through the phagosome maturation process. Cell Microbiol. 2004;6:973-85.

71. Vergne I, Chua J, Lee HH, Lucas M, Belisle J, Deretic V. Mechanism of phagolysosome biogenesis block by viable Mycobacterium tuberculosis. Proc Natl Acad Sci USA. 2005;102:4033-8.

72. Kang PB, Azad AK, Torrelles JB, Kaufman TM, Beharka A, Tibesar E, et al. The human macrophage mannose receptor directs Mycobacterium tuberculosis lipoarabinomannan-mediated phagosome biogenesis. J Exp Med. 2005;202:987-99.

73. Chavrier P, Parton RG, Hauri HP, Simons K, Zerial M. Localization of low molecular weight GTP binding 
proteins to exocytic and endocytic compartments. Cell. 1990;62:317-29.

74. Bottger G, Nagelkerken B, van der Sluijs P. Rab4 and Rab7 define distinct nonoverlapping endosomal compartments. J Biol Chem. 1996;271:29191-7.

75. Vitelli R, Santillo M, Lattero D, Chiariello M, Bifulco M, Bruni CB, et al. Role of the small GTPase Rab7 in the late endocytic pathway. J Biol Chem. 1997;272:4391-7.

76. Meresse S, Gorvel JP, Chavrier P. The Rab7 GTPase resides on a vesicular compartment connected to lysosomes. J Cell Sci. 1995;108:3349-58.

77. Bucci C, Thomsen P, Nicoziani P, McCarthy J, van Deurs B. Rab7: a key to lysosome biogenesis. Mol Biol Cell. 2000;11:467-80.

78. Feng Y, Press B, Wandinger-Ness A. Rab 7: an important regulator of late endocytic membrane traffic. J Cell Biol. 1995;131:1435-52.

79. Press B, Feng Y, Hoflack B, Wandinger-Ness A. Mutant Rab7 causes the accumulation of cathepsin D and cationindependent mannose 6-phosphate receptor in an early endocytic compartment. J Cell Biol. 1998;140:1075-89.

80. Cantalupo G, Alifano P, Roberti V, Bruni CB, Bucci C. Rab-interacting lysosomal protein (RILP): the Rab7 effector required for transport to lysosomes. Embo J. 2001;20:683-93.

81. Jordens I, Fernández-Borja M, Marsman M, Dusseljee S, Janssen L, Calafat J, et al. The Rab7 effector protein RILP controls lysosomal transport by inducing the recruitment of dynein-dynactin motors. Curr Biol. 2001;11:1680-5.

82. Harrison RE, Bucci C, Vieira OV, Schroer TA, Grinstein S. Phagosomes fuse with late endosomes and/or lysosomes by extension of membrane protrusions along microtubules: role of Rab7 and RILP. Mol Cell Biol. 2003;23:6494-506.

83. Saito F, Kuwata H, Oiki E, Koike M, Uchiyama Y, Honda $\mathrm{K}$, et al. Inefficient phagosome maturation in infant macrophages. Biochem Biophys Res Commun. 2008;375:113-8.

84. Scianimanico S, Desrosiers M, Dermine JF, Meresse S, Descoteaux A, Desjardins M. Impaired recruitment of the small GTPase Rab7 correlates with the inhibition of phagosome maturation by Leishmania donovani promastigotes. Cell Microbiol. 1999;1:19-32.

85. Clemens DL, Lee BY, Horwitz MA. Mycobacterium tuberculosis and Legionella pneumophila phagosomes exhibit arrested maturation despite acquisition of Rab7. Infect Immun. 2000;68:5154-66.

86. Hmama Z, Sendide K, Talal A, Garcia R, Dobos K, Reiner NE. Quantitative analysis of phagolysosome fusion in intact cells: inhibition by mycobacterial lipoarabinomannan and rescue by an 1alpha,25-dihydroxyvitamin D3phosphoinositide 3-kinase pathway. J Cell Sci. 2004; 117:2131-40

87. Sun J, Deghmane AE, Soualhine H, Hong T, Bucci C, Solodkin A, et al. Mycobacterium bovis BCG disrupts the interaction of Rab7 with RILP contributing to inhibition of phagosome maturation. J Leukoc Biol. 2007;82:1437-45.

88. Ullrich O, Reinsch S, Urbe S, Zerial M, Parton RG. Rab11 regulates recycling through the pericentriolar recycling endosome. J Cell Biol. 1996;135:913-24.
89. Ren M, Xu G, Zeng J, De Lemos-Chiarandini C, Adesnik M, Sabatini DD. Hydrolysis of GTP on Rab11 is required for the direct delivery of transferrin from the pericentriolar recycling compartment to the cell surface but not from sorting endosomes. Proc Natl Acad Sci USA. 1998;95:6187-92.

90. Cox D, Lee DJ, Dale BM, Calafat J, Greenberg S. A Rab11containing rapidly recycling compartment in macrophages that promotes phagocytosis. Proc Natl Acad Sci USA. 2000;97:680-5.

91. Tailleux L, Neyrolles O, Honore-Bouakline S, Perret E, Sánchez F, Abastado JP, et al. Constrained intracellular survival of Mycobacterium tuberculosis in human dendritic cells. J Immunol. 2003;170:1939-48.

92. Fratti RA, Vergne I, Chua J, Skidmore J, Deretic V. Regulators of membrane trafficking and Mycobacterium tuberculosis phagosome maturation block. Electrophoresis. 2000;21:3378-85.

93. Roberts EA, Chua J, Kyei GB, Deretic V. Higher order Rab programming in phagolysosome biogenesis. J Cell Biol. 2006;174:923-9.

94. Junutula JR, De Maziere AM, Peden AA, Ervin KE, Advani RJ, van Dijk SM, et al. Rab14 is involved in membrane trafficking between the Golgi complex and endosomes. Mol Biol Cell. 2004;15:2218-29.

95. Kyei GB, Vergne I, Chua J, Roberts E, Harris J, Junutula JR, et al. Rab14 is critical for maintenance of Mycobacterium tuberculosis phagosome maturation arrest. Embo J. 2006;25:5250-9.

96. Lombardi D, Soldati T, Riederer MA, Goda Y, Zerial M, Pfeffer SR. Rab9 functions in transport between late endosomes and the trans Golgi network. Embo J. 1993;12:677-82.

97. Riederer MA, Soldati T, Shapiro AD, Lin J, Pfeffer SR. Lysosome biogenesis requires Rab9 function and receptor recycling from endosomes to the trans-Golgi network. J Cell Biol. 1994;125:573-82.

98. Brunt LM, Portnoy DA, Unanue ER. Presentation of Listeria monocytogenes to CD8+ T cells requires secretion of hemolysin and intracellular bacterial growth. J Immunol. 1990;145:3540-6.

99. Rojas M, García LF, Nigou J, Puzo G, Olivier M. Mannosylated lipoarabinomannan antagonizes Mycobacterium tuberculosis-induced macrophage apoptosis by altering $\mathrm{Ca}+2$-dependent cell signaling. J Infect Dis. 2000;182:240-51.

100. Steinberg BE, Grinstein S. Pathogen destruction versus intracellular survival: the role of lipids as phagosomal fate determinants. J Clin Invest. 2008;118:2002-11.

101. Huynh KK, Gershenzon E, Grinstein S. Cholesterol accumulation by macrophages impairs phagosome maturation. J Biol Chem. 2008;283:35745-55.

102. Jacobsen M, Repsilber D, Gutschmidt A, Neher A, Feldmann K, Mollenkopf HJ, et al. Ras-associated small GTPase 33A, a novel T cell factor, is down-regulated in patients with tuberculosis. J Infect Dis. 2005;192:1211-8. 